\title{
Models for Estimation of Service Life of Concrete Barriers in Low-Level Radioactive Waste Disposal
}

Manuscript Completed: July 1990

Date Published: September 1990

Prepared by

J. C. Walton, L. E. Plansky, R. W. Smith

Idaho National Engineering Laboratory

Managed by the U.S. Department of Energy

EG\&G Idaho, Inc.

P.O. Box 1625

Idaho Falls, ID 83415

Prepared for

Division of Engineering Office of Nuclear Regulatory Research

U.S. Nuclear Regulatory Commission

Washington, DC 20555

NRC FIN A6858

\author{
DISCLAIMER
}

This report was prepared as an account of work sponsored by an agency of the United States Government. Neither the United States Government nor any agency thereof, nor any of their employees, makes any warranty, express or implied, or assumes any legal liability or responsibility for the accuracy, completeness, or usefulness of any information, apparatus, product, or process disclosed, or represents that its use would not infringe privately owned rights. Reference herein to any specific commercial product; process, or service by trade name, trademark, manufacturer, or otherwise does not necessarily constitute or imply its endorsement, recommendation, or favoring by the United States Government or any agency thereof. The views and opinions of authors expressed herein do not necessarily state or reflect those of the United States Government or any agency thereof. 


\begin{abstract}
Concrete barriers will be used as intimate parts of systems for isolation of low-level radioactive wastes subsequent to disposal. This work reviews mathematical models for estimating the degradation rate of concrete in typical service environments. The models considered cover sulfate attack, reinforcement corrosion, calcium hydroxide leaching, carbonation, freeze/thaw, and cracking. Additionally, fluid flow, mass transport, and geochemical properties of concrete are briefly reviewed. Example calculations included illustrate the types of predictions expected of the models.
\end{abstract}

FIN No. A6858 - Performance of Concrete Barriers in Low-Level Waste Disposal 


\section{Summary}

Concrete barriers are likely to be incorporated into low-level radioactive waste disposal facilities as structural components and barriers to fluid flow and mass transport of radionuclides. Analysis of the role of the concrete barriers in low-level waste isolation requires that performance assessment models be applied to concrete degradation. Because the history of modern concrete is short ( $\sim 100$ years) relative to the required prediction of service life, the task is difficult and subject to uncertainty.

This report consists of a critical review of mathematical models that predict concrete material properties over long time periods. Models obtained from the literature are explained in enough detail to illustrate derivation and basic assumptions. Additional example calculations are included to illustrate application of the models and to indicate the types of predictions that can be expected from the models.
Degradation processes important to waste isolation include sulfate attack, reinforcement corrosion, leaching, carbonation, freeze thaw, and stress cracking. A brief review of mass transport and fluid flow through concrete is provided. The transport material provides consistent nomenclature for the calculations in the models. Examples of the range of water chemistry expected in subsurface environments in the United States and an overview of concrete pore water chemistry and its potential influence on radionuclide mobility are provided. Basic knowledge of concrete chemistry is necessary for applying the degradation models. The background sections are followed by individual chapters covering the mathematical models for each class of degradation. A future report will evaluate the implications of degradation and general design for performance of the concrete vault. 


\section{Acknowledgements}

The authors would like to thank Shirley A. Rawson for review and input to the work and Tim McCartin, NRC project manager. 


\section{Contents}

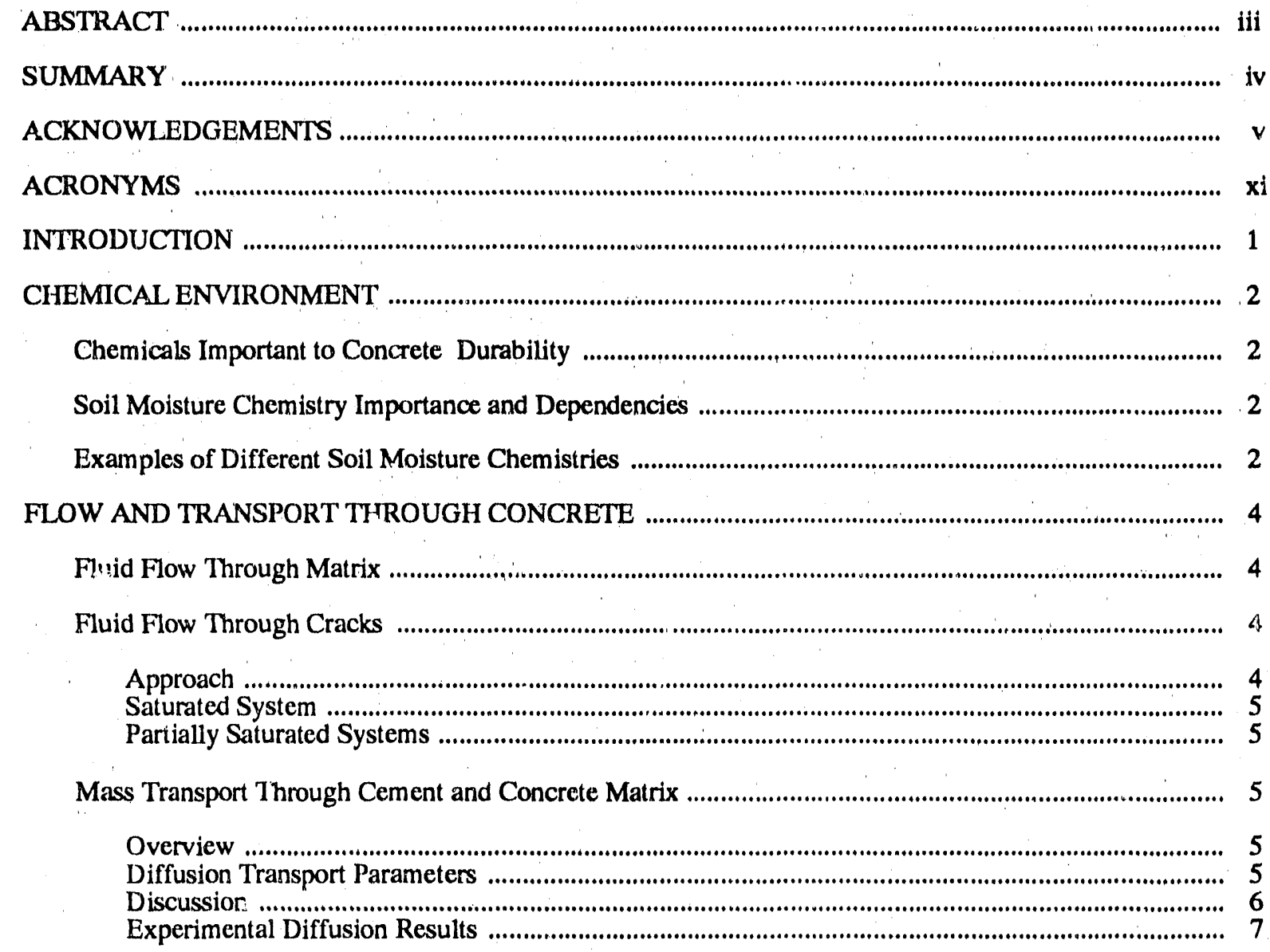

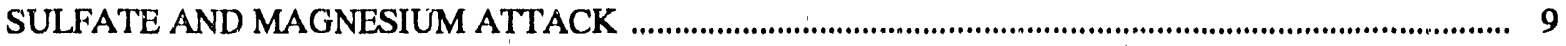

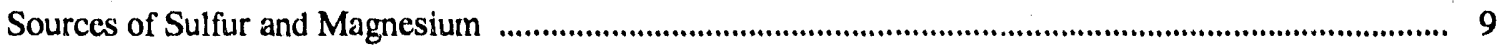

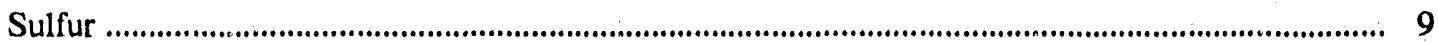

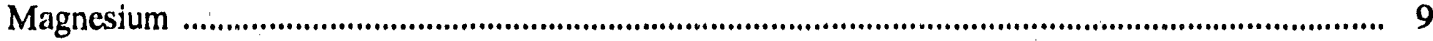

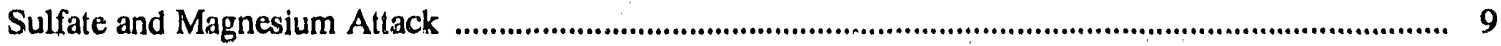

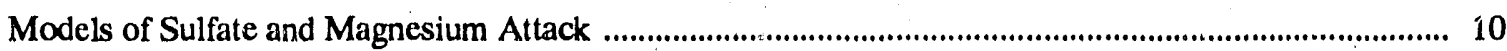

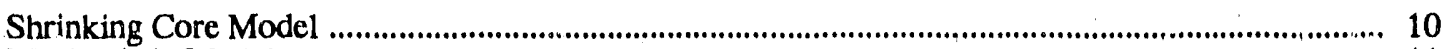

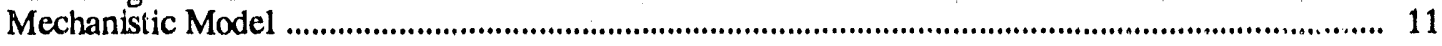

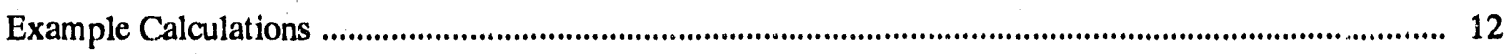

REINFORCEMENT CORROSION/CHLORIDE ATTACK _............................................................. 14

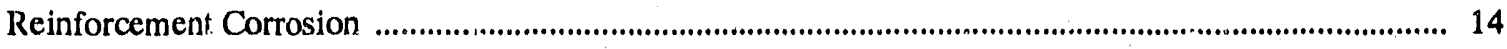

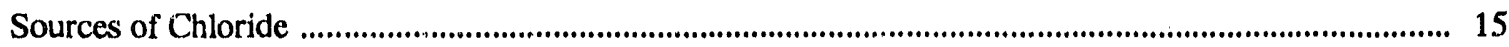

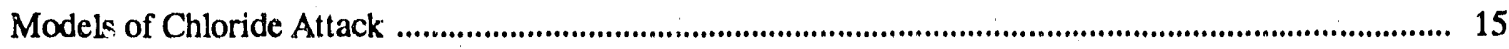

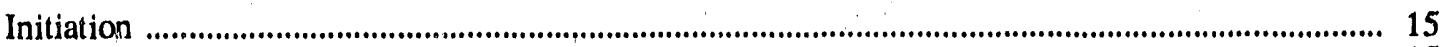

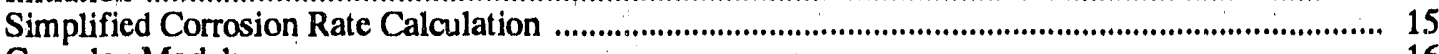

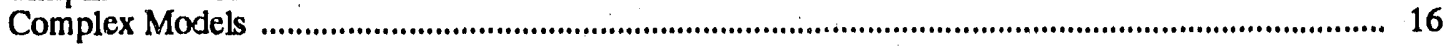




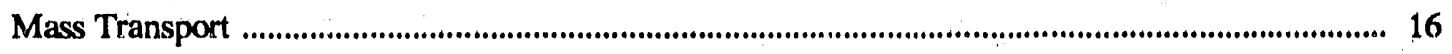

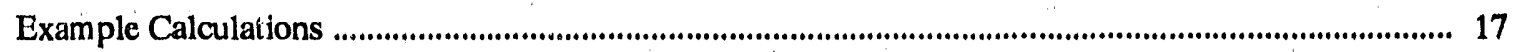

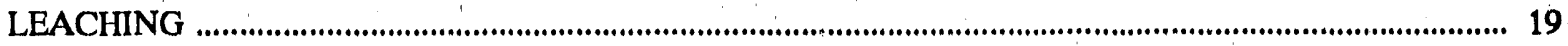

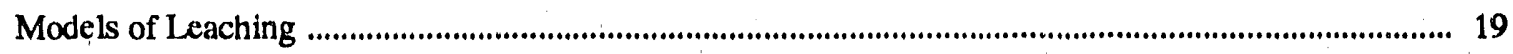

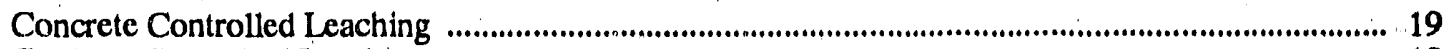

Geology Controlled Leaching ........................................................................................................ 19

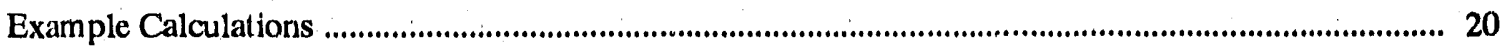

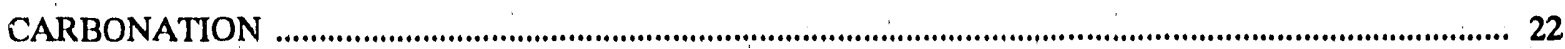

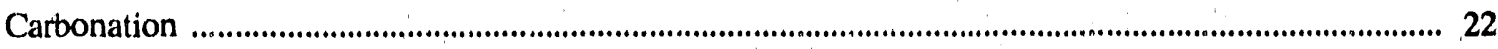

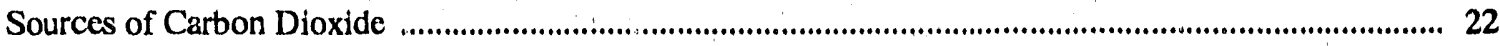

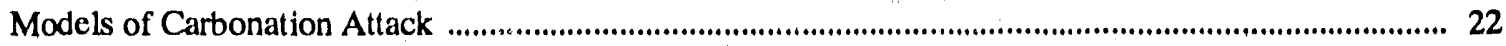

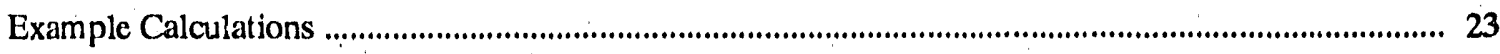

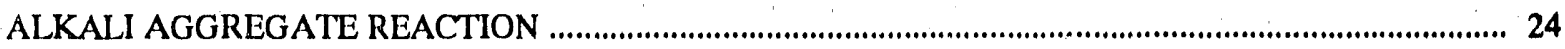

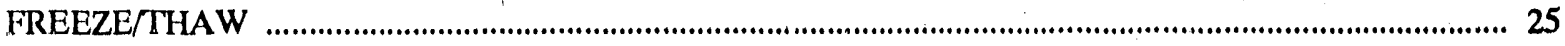

Models of Freeze/Thaw Performance ................................................................................................ 25

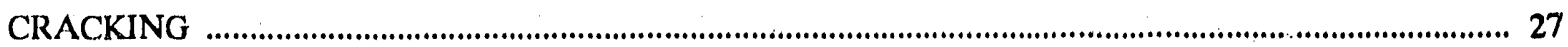

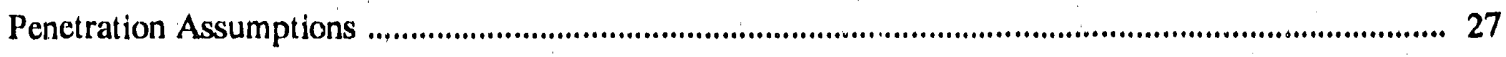

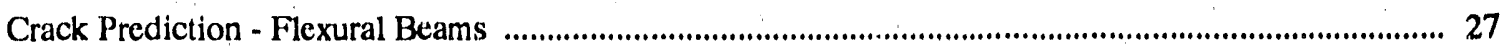

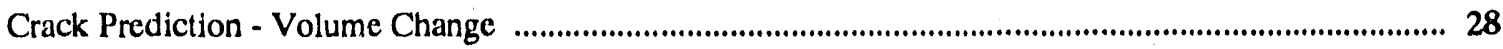

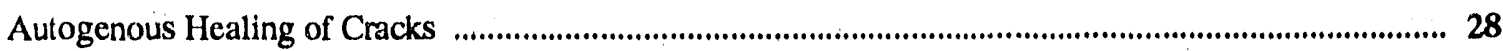

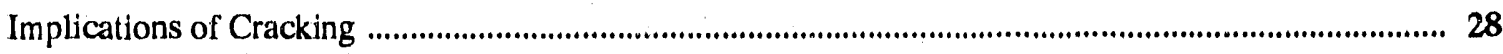

\section{CONCRETE CHEMISTRY, RADIONUCLIDES, AND NEAR FIELD EFFECTS}

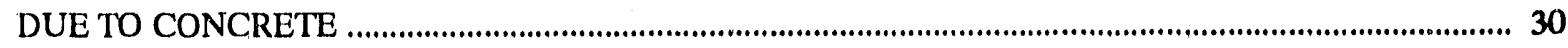

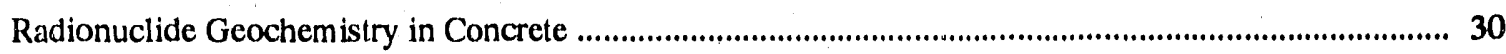

Chemical and Physical Properties of Concrete .............................................................................. 30

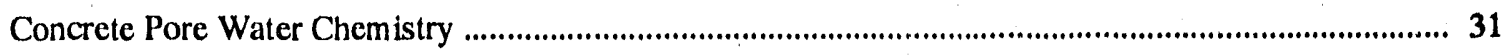

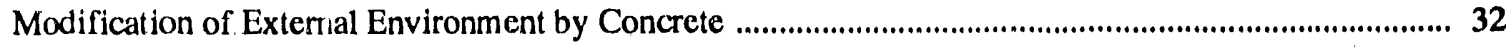

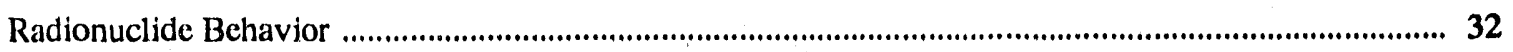

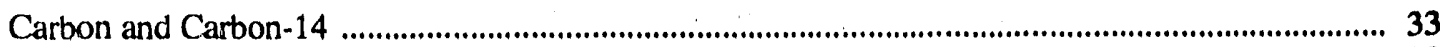

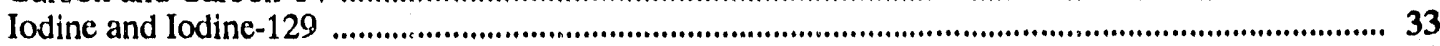

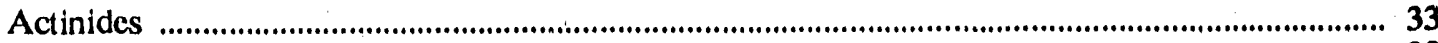

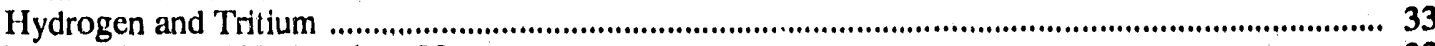

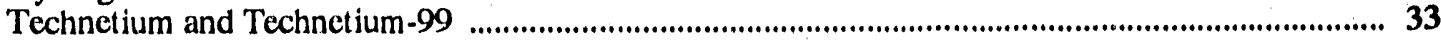

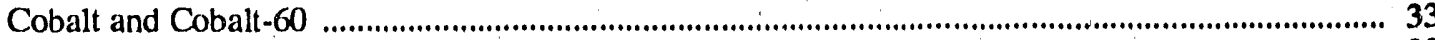

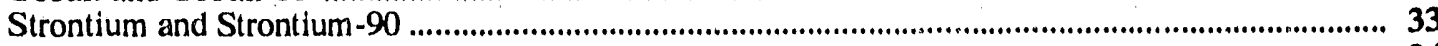

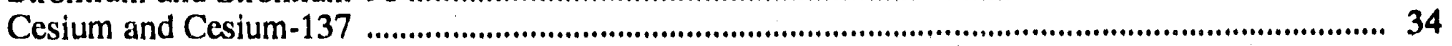


Summary

SUMMARY AND CONCLUSIONS .

35

BIBLIOGRAPHY

36 


\section{Figures}

1. Suction head for crack drainage under partially saturated conditions ........................................................ 4

2. Individual crack hydraulic conductivity for concretc as a function of crack width ..................................... 5

3. Intrinsic diffusion coefficient in cement paste as a function of WCR ........................................................... 7

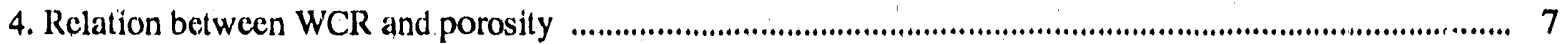

5. Estimated tortuosity factor for cement as a function of WCR _............................................................ 8

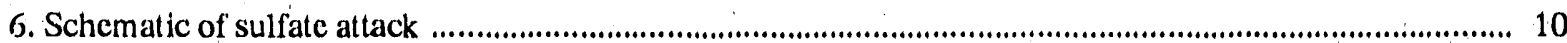

7. Estimates of sulfate attack in a low sulfate environment based upon empirical model .............................. 12

8. Estimates of sulfate attack rate in a midrange sulfate environment based upon emprirical model ................ 12

9. Estimates of sulfate attack rate in a high sulfate environment based upon empirical model ...................... 12

10. Estimates of sulfate attack rate based upon mechanistic model of sulfate attack ....................................... 13

11. Schematic of chloride attack on steel reniforcement .........................................................................

12. Time to initiation of reinforcement corrosion by emprical model as a function of WCR and depth of cover with soil chloride concentration of 1 ppm. ............................................................................. 17

13. Time to initiation of reinforcement corrosion by empirical model with $50 \mathrm{ppm}$ chloride in soil moisture

14. Time to initiation of reinforcement corrosion by empirical model with $30,00 \mathrm{ppm}$ chloride in soil moisture

15. Example of oxygen limited corrosion rate subsequent to initiation of corrosion

16. Schematic of calcium hydroxide leaching 20

17. Calcium hydroxide leaching assuming concrete control in northeast, midwest, and arid environments

18. Calcium hydroxide leaching assuming geology control ...................................................................... 21

19. Rate of carbonation by shrinking core model in different geochemical environments ................................ 23

20. Loss from freeze/thaw damage with 7\% entrained air ............................................................................ 26

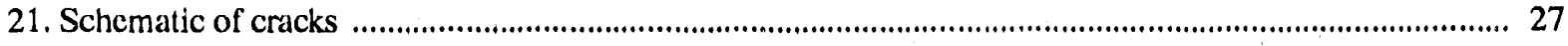

22. Change in $\mathrm{pH}$ with time as predicted by Atkinson et al., 1987. ............................................................ 31

23. Effect of pH on distribution coefficient of conditioned clay ................................................................... 32

24. Effect of $\mathrm{pH}$ on distribution coefficient of conditioned clinoptilolite ...................................................... 32 


\section{Tables}

1. Categories of concrete degradation phenomena _............................................................................... 1

2. Water chemistry characteristic of several locations in the United States ...................................................... 3

3. Volume changes resulting from steel corrosion ..................................................................................... 14

4. Properties and constituents of example concretes ..................................................................................... 30

5. Chemical composition limits of Portland cements ...................................................................................... 31

6. Measured ranges of pore-water compositions of hydrated cements ....................................................................... 32 


\section{Acronyms}

ACI American Concrete Institute

ASTM American Society for Testing and Materials

BFS Blast furnace slag

$\mathrm{CSH}$ Calcium silicate hydrate

DME Dyanmic modulus of elasticity
LLW Low-level waste

OPC Ordinary Portland Cement

PCA Portland Cement Association

SRPC Sulfate Resistant Portland Cement

WCR Water-to-cement ratio 


\section{MODELS FOR ESTIMATION OF SERVICE LIFE OF CONCRETE BARRIERS IN LOW-LEVEL RADIOACTIVE WASTE DISPOSAL}

\section{INTRODUCTION}

Concrete barriers are likely to be incorporated into low-level radioactive waste disposal facilities as structural components and barricrs to fluid flow and mass transport of radionuclides. Analysis of the role of the concrete barriers in low-level waste (L,L,W) isolation requires that performance assessment models be applied to concrete degradation. Because the history of modern concrete is short ( 100 years) relative to the required prediction of service life, the task is difficult. The task is made even more difficult by the great importance of quality assurance and workmanship. Thesc aspects are of crucial importance to durability but difficult to quantify and include in models. Another large problem is that the majority of models tend to be empirical in nature. Because the determinations of service life are of necessity longer than the empirical database, the empirical models are almost always applied outside the bounds of the intial data. Blind extrapolation of empirical data is difficult to defend technically, but is frequently the only option to no prediction at all.

This report consists of a critical review of mathematical models that predict concrete material properties over long time periods. Models obtained from the literature are explained in enough detail to illustrate derivation and basic assumptions. Additional example calculations are included to illustrate application of the models and to indicate the types of predictions that can be expected from the models.

Degradation processes important to waste isolation are listed in Table 1. Models have been found that attempt to cover sulfate altack, reinforcement corrosion, leaching, carbonation, freez/thaw, and stress cracking. A brief revicw of mass transport and fluid flow through concrete is provided. This transport material provides consistent nomenclature for the calculations in the models. Examples of the range of water chemistry expected in subsurface environments in the United States and an overview of concretc pore water chemistry and its potential inlluence on radionuclide mobility are provided. Basic knowledge of concrete chemistry is necessary for application of the degradation models.

The background sections are followed by individual chapters covering the mathematical models for each class of degradation. Example calculations and graphs are included in several sections and illustrate the types and range of predictions to be expected frorn some of the models. These calculations are nominally organized along the lines of vaults located in different portions of the United States; however, associations between soil chemistry and region are approximate. A future report will evaluate the implications of degradation and general design for performance of the concrete vault.

Table 1. Categories of concrete degradation phenomena

\begin{tabular}{ll}
\hline Sulfate Altack & Carbonation \\
\hline $\begin{array}{l}\text { Reinforcement Corrosion } \\
\text { (Chloride Allack) }\end{array}$ & $\begin{array}{l}\text { Skrinkage Cracking } \\
\text { Thermal Cracking } \\
\text { Miscellaneous Cracking }\end{array}$ \\
$\begin{array}{l}\text { Stress Cracking } \\
\text { Leaching of Concrete }\end{array}$ & $\begin{array}{l}\text { Alkali-Aggregate Reaction } \\
\text { Fonstitucnts }\end{array}$ \\
Acid Attack & Oxidation and \\
& Biodegradation of Coatings \\
& and Sealants
\end{tabular}




\section{CHEMICAL ENVIRONMENT}

\section{Chemicals Important to Concrete Durability}

The loss of durability of concrete is caused either by the external environment or internal causes. The external causes can be physical, chemical, or mechanical. Internal causes of degradation are the alkali-aggregate reaction, volume changes due to differences in thermal properties of aggregate and cement paste, and most importantly, the permeability of the concrete. Permeability of the concrete is important in limiting mass transport of corrosive agents (c.g., sulfate, chloride) into the concrete and leaching of cement components [e.g., $\mathrm{Ca}(\mathrm{OH})_{2}$ ] from the concrete.

The near field environment, as considered herein, constitutes the soil and soil moisture conditions directly surrounding and in contact with the concrete structure as well as the wastes contained inside the concrete valtt. The near field environment is considered from the perspective of the concrete.

A number of chemicals are important to concrete degradation. These have been identified by the American Concrete Institute $(\mathrm{ACl})$ and summarized by the Portland Cement Association (PCA) (PCA, 1986). In general, most acids attack either the ecment itself or the steel reinforcement. Salts and alkalies known to cause degradation include: salts containing sulfate, bisulfite, cyanide, dichromate, fluoride, hexamctaphosphate, nitrate, or chloride ions; sodium perborate, sodium perchlorate, potassium persulfate, sodium phosphate, thiosulfate; ammonium superphosphate; and borax. Petroleum oils generally do not lead to degradation; some coal tar distillates such as creosote may cause slow disintegration. Most solvents and alcohols do not lead to degradation. Exceptions are carbon disulfide, glycerin, and ethylene glycol, which lead to slow degradation. Many vegetable and animal oils lead to concrete degradation.

In typical disposal situations, the ions in the soil environment of greatest concern are sulfate, chloride, carbon dioxide, and magnesium. Because these ions are ubiquitous, model development has focused on their effects. In general, mathamatical models are not available to evaluate the concrete degradation caused by the multiple other chemicals that could be present in the waste. Current models have been developed almost entirely from the perspective of external altack on the concrete from the soil side.

\section{Soil Moisture Chemistry Importance and Dependencies}

Soil moisture levels and the chemistry of soil moisture are important to the siting of waste repositories. Soll moisture can be an important transport medium for radionuclides. It can affect the performance of a disposal site through chemical degradation phenomena, such as sulfate or chloride attack. Soll pH and th also affect the sorption and precipitation mechanisms that can control radionuclide mobility.

The soil moisture chemistry of a potential disposal site is dependent upon environmental factors. These factors include soil source material, drainage, proximity to oceans, and climate, especialiy the balance between precipitation and evapotranspiration. In humid environments, soils become leached of soluble salts, leading to low ion concentrations in soil moisture. As precipitation rates fall relative to evaporation, soluble salts begin to accumulate in the soil, leading in extieme cases to saline soils. Although climate is very important, source rock type, drainage, and location are also of great importance. Locations near cceans typically experience higher chloride levels.

\section{Examples of Different Soil Moisture Chemistries}

Examples of soil moisture chemistry at different locations in the United States (Table 2) were obtained fron several sources. These data represent chemical analyses of stream flow, springs, soil mcisture collected from suction lysimeters, and precipitation. Stream flow represents a composite of precipitation, runoff, and infiltrated water. In humid regions, this is a reasonable estimate of typical soil water composition. In arid, mountainous regions, stream flow may be dominated by snowmelt and runoff that will differ greatly from soil moisture in chemical composition.

The data indicate arid regions may have increased concentrations of chloride and sulfate, making them much more aggressive towards concrete. The aggressive composition of the soll moisture in arid regions is balanced against lower infiltration rates and amounts of moisture that contact the concrete.

Processes such as leaching are relatively more important in humid situations whereas arid environments may produce specific attack on the concrete barrier components (e.g., sulfate attack, chloride attack). 
Table 2. Water chemistry characteristic of several locations in the United States.

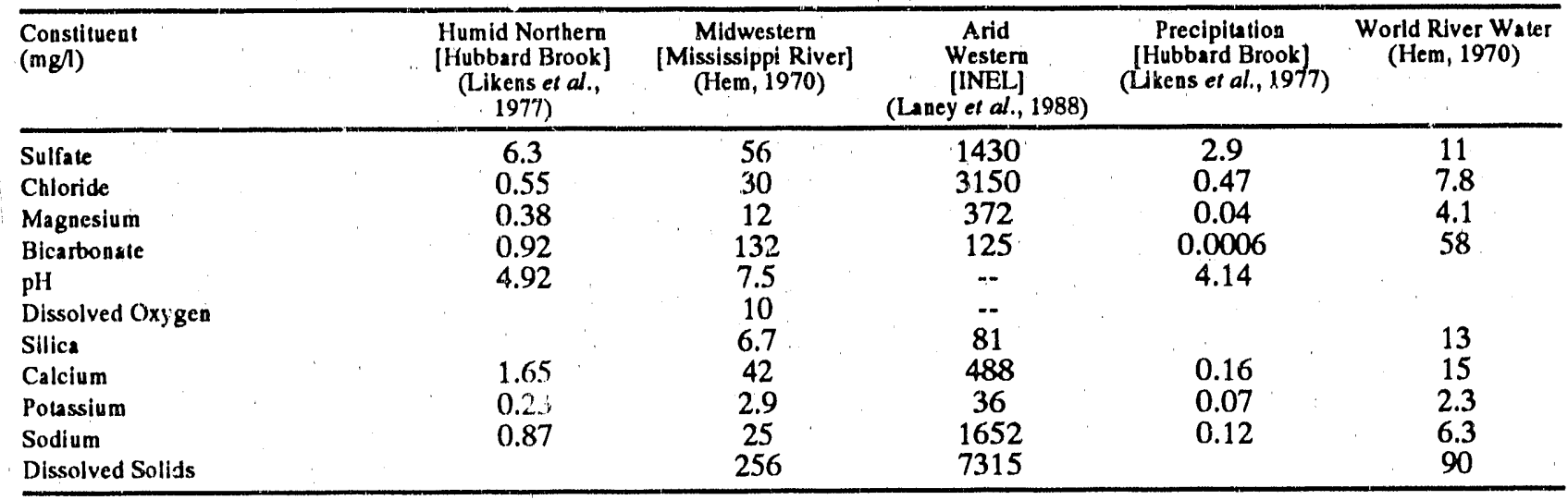

\begin{tabular}{|c|c|c|c|c|c|c|}
\hline $\begin{array}{l}\text { Constituent } \\
\text { (Horne, 1978) } \\
(\mathrm{ppm}) \\
\end{array}$ & $\begin{array}{l}\text { Big Spring, } \\
\text { Huntsville, AL } \\
\text { Limestone }\end{array}$ & $\begin{array}{c}\text { Jumping Springs, } \\
\text { Eddy County, NM } \\
\text { Gypsum }\end{array}$ & $\begin{array}{l}\text { Cooks Springs, } \\
\text { Colusa, CA } \\
\text { Serpentine }\end{array}$ & $\begin{array}{c}\text { Well, San Miguel } \\
\text { County, NM } \\
\text { Shale }\end{array}$ & $\begin{array}{l}\text { Sait Banks; } \\
\text { Chrysotile, AR }\end{array}$ & $\begin{array}{l}\text { Well, Owybye } \\
\text { County, ID }\end{array}$ \\
\hline Sulfate & 4.0 & 1570 & 6.0 & 303 & 882 & 30 \\
\hline Chloride & 3.5 & 24 & 390 & 80 & 16,000 & 10 \\
\hline Magnesium & 4.2 & 43 & 614 & 31 & 286 & 1.4 \\
\hline Bicarbonate & 146 & 143 & 4090 & 445 & 1,490 & 111 \\
\hline $\mathrm{pH}$ & 7.0 & & & & 7.1 & 9.2 \\
\hline Silica & 8.4 & 29 & 80 & 13 & 45 & 99 \\
\hline Calcium & 46 & 636 & 26 & 30 & 496 & 2.4 \\
\hline Dissolved Solids & 139 & 2,410 & 3760 & 973 & 28,400 & 348 \\
\hline
\end{tabular}




\section{FLOW AND TRANSPORT THROUGH CONCRETE}

Fluid flow and mass transport through a concrete vault are two of the most important factors influencing concrete degradation rates and the ability of the concrete to assist with isolation of the waste. Over time as a concrete vault ages, the properties of the concrete and its ability to assist with isolation of the waste will change. Portions of the concrete will crumble and become more permeable. Eventually cracks will penetrate the concrete slabs, leading to preferential pathways through the barrier. This section reviews some "te aspects of flow and transport through concrete that are hevant to understanding the mathematical models for concrete degradation. The performance implications of the degradation phenomena will be treated in more detail in a future document.

\section{Fluid Flow Through Matrix}

The rate of water percolation through a waste isolation system is one of the most important measures of performance. Initial matrix permeability of cement paste is influenced strongly by water-to-cement ratio (WCR) with its influence upon capillary porosity (Powers, 1958 and $1960)$. Evaluation of fluid flow is complicated by location of the low-level waste (LLW) facilities in the unsaturated zone.

Flow through the unsaturated zone can be described using the Richard's equation (Hillel, 1971).

$\frac{\partial \theta}{\partial t}=\frac{\partial}{\partial x}\left(K(\psi) \frac{\partial \psi}{\partial x}\right)+\frac{\partial}{\partial z}\left(K(\psi)\left(\frac{\partial \psi}{\partial z}-1\right)\right)$

where

$\psi=\operatorname{pressure~head~}(\mathrm{cm})$

$\theta=$ volumetric water content

$K=$ hydraulic conductivity $(\mathrm{cm} / \mathrm{s})$.

Concrete differs from other components of the vault system (e.g., soils) in that typical pore sizes in concrete are very small. Typical soils can be dried to near the residual saturation at soil tensions of a few bars (Wosten and van Genuchten, 1988), while removal of water from cement or concrete requires tensions of hundreds to thousands of bars (Daian, 1988). For example, concrete can maintain $85 \%$ saluration at tensions of 9 bars (Daian, 1988). The small pore sizes are especially characteristic of low WCR concretes used for concrete barriers. In subsurface environments, the small pores in the concrete successively remove water from the surrounding materials leading to saturation of the concrete matrix. The concrete matrix remains near saturation even when the surrounding soils are quite dry.
The hydraulic conductivity of gel pores is approximately $7 \times 10^{-16} \mathrm{~m} / \mathrm{s}$ (Powers, 1958). The permeability of the cement paste is a function of capillary porosity. Capillary porosity in tum is dependent upon the WCR and degree of hydration. Typical cerient paste has a permeability of 20 to 100 times the minimum (Powers, 1958). In general, the hydraulic conductivity of concrete with a low WCR should be less than $10^{-12} \mathrm{~m} / \mathrm{s}$.

\section{Fluid Flow Through Cracks}

Approach. Even in relatively minor amounts, cracking can lead to orders of magnitude increases in saturated hydraulic conductivity of concrete. If the concrete is one of the more significant barriers to flow through the system, the increase in hydraulic conductivity can lead to proportional increases in water percolation through the system.

Location of the LLW facilities in the unsalurated zone greatly complicates the role of cracks in influencing performance of concrete barriers. In unsaturated environments, water remains in a state of tension created by capillary action (absorption) and adsorption. Because cracks are large relative to the pore size of the matrix, they have a limited ability to hold water in tension. In other words, under unsaturated conditions cracks will drain quickly. The drained cracks not only no longer contribute to flow but may also serve as barriers to flow (Wang and Narasimhan, 1985). Depending upon the degree of saturation, cracks may range from orders of magnitude increases in flow rate to significant decreases in flow relative to an uncracked specimen. The ability of cracks to hold water (and thereby contribute to flow) as a function of pressure head is illustrated in Figure 1.

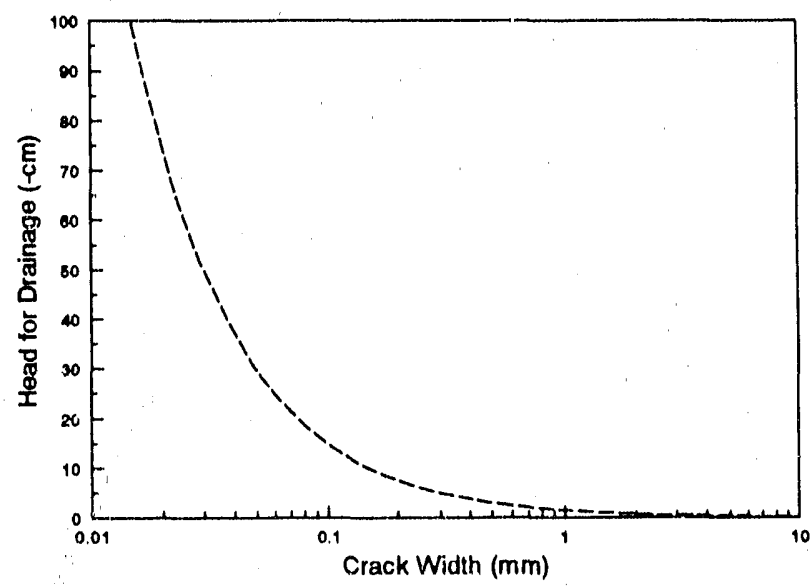

Figure 1. Suction head for crack drainage under partially saturated conditions. 
Saturated System. The permeability of intact concrete with low water to cement ratio is very low. For this reason, cracks, particularly microcracks, are thought to actually control concrete permeability in service environments. Microcracks are caused by a variety of phenomena including response of concrete and reinforcement bars to physical loading, drying shrinkage, and expansion/contraction from temperature changes.

If an infinitely long, parallel sided crack thiough the concrete is assumed, the flow though a crack is

$K=\frac{\rho g b^{2}}{12 \mu}$

where

$$
\begin{aligned}
& \mathrm{K}=\text { hydraulic conductivity }(\mathrm{cm} / \mathrm{s}) \\
& \rho=\text { density of water }\left(\mathrm{g} / \mathrm{cm}^{3}\right) \\
& \mathrm{g}=\text { acueleration of gravity }\left(980 \mathrm{~cm} / \mathrm{s}^{2}\right) \\
& \mathrm{b}=\text { fractur: aperture }(\mathrm{cm}) \\
& \mu=\text { viscosity of water }(-0.01 \mathrm{~g} / \mathrm{cm} \mathrm{s})
\end{aligned}
$$

Studies of flow through cracks in concrete slabs have shown that actual flow is typically $1 / 3$ to $2 / 3$ of the theoretical value (Loadsman et al., 1988). A value of $1 / 2$ is applied giving (Figure 2)

$K=\frac{\rho g b^{2}}{24 \mu}$.

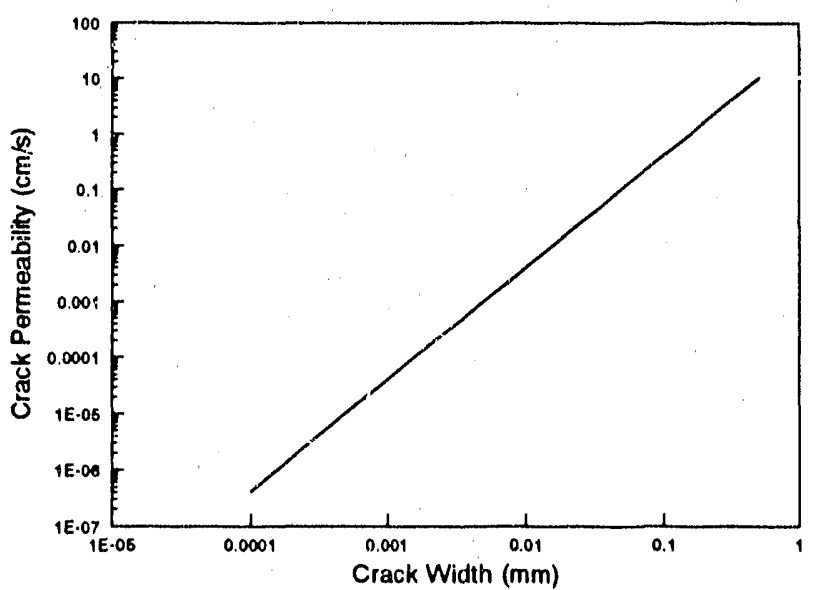

Figure 2. Individual crack hydraulic conductivity for concrete as a function of crack width.

More generally desirable is the contribution of a series of cracks to overall or average permeability of a slab. If $s$ is the crack spacing ( $\mathrm{cm} / \mathrm{crack}$ ) for evenly spaced cracks of constant aperture, then the proportional area of cracks is $A_{1}=b / s$, and the bulk permeability of the cracked slab is

$K=\frac{\rho g b^{3}}{24 \mu s}+K_{m a t}$.
Usually the matrix permeability $\left(\mathrm{K}_{\mathrm{mot}}\right)$ is much less than the crack permeability and can be ignored.

Partially Saturated Systems. The above analysis assumes that all cracks are saturated. For concrete vaults located in the unsaturated zone, this is not always the case. The pressure head for drainage of a crack of width $b$ is

$h=\frac{-2 \gamma \cos (\alpha)}{b \rho g}$

where

$\gamma=$ surface tension of water $(72.7 \mathrm{dyne} / \mathrm{cm})$

$\alpha=$ cement water contact angle (assumed $=0$ )

$\mathrm{h}=$ pressure head $(\mathrm{cm})$.

Thus, the crack width giving permeability increase at any given pressure head is the greatest width that will not be drained or

$b_{\text {max } \text { Ilow }}=\frac{-2 \gamma \cos (\alpha)}{h \rho g}-\frac{-0.148\left[\mathrm{~cm}^{2}\right]}{h}$.

\section{Mass Transport Through Cement and Concrete Matrix}

Overview. The primary modes of radionuclide transport in an intact concrete are advection/dispersion and diffusion through the matrix. The transport of fluids and chemicals through the concrete is also the single most important factor in controlling concrete degradation. This is evidenced by the importance of WCR - which determines the final concrete porosity and permeability to durability (Powers, 1960).

Other modes of transport that may become significant are nonaqueous liquid phase movement (e.g., organic liquids in the waste) and gascous transport. An example of gaseous transport scenario is when tritiated water reacts with steel containers and/or reinforcement bars leading to the formation of hydrogen gas

$3 \mathrm{Fe}(\mathrm{c})+4 \mathrm{H}_{2} \mathrm{O} \Rightarrow \mathrm{Fe}_{3} \mathrm{O}_{4}(\mathrm{c})+4 \mathrm{H}_{2}(\mathrm{~g})$.

The rate of escape of the hydrogen gas is then important to system performance. Gascous transport can also be significant in influencing the oxidation-reduction status of the interior of the vault. Oxidation-reduction conditions in lurn are important in influencing metal corrosion rates and radionuclide mobility (solubility/sorption).

Diffusion Transport Parameters. In relatively impermeable materials such as intact concrete, the rate of water flow is very low. In low flow situations, diffusional transport according to Fick's laws of diffusion will dom inate mass transport. Diffusion of dissolved species can occur in either the gaseous or liquid phase. Because of the small pore sizes concrete matrix present in belowground vaults remains near saturation with water even when the surrounding soil 
materials are relatively dry. Thus, it is anticipated that most diffusional transport in subsurface concrete barriers will be through the liquid phase, irrespective of whether the vault is located above or below the water table.

The general transport equation for aqueous transport assuming linear partitioning between liquid and solid is (Codell and Duguid, 1983)

$\theta \frac{\partial C}{\partial t}=\frac{1}{R_{d}} \vec{\nabla} \cdot\left(\theta D_{E} \vec{\nabla} C-\vec{V} C\right)-C \frac{\partial \theta}{\partial t}-\lambda \theta C$.

The retardation factor is given by

$R_{d}=1+\frac{\rho_{b}}{\theta} K_{d}$

where

$$
\begin{aligned}
& R_{d}=\text { retardation factor } \\
& C=\text { concentration }\left(\mathrm{g} / \mathrm{cm}^{3}\right) \\
& \lambda=\text { decay constant }\left(\mathrm{s}^{-1)}\right. \\
& K_{d}=\text { distribution cocfficient }(\mathrm{ml} / \mathrm{g}) \\
& D_{E}=\text { effective dispersivity } / \text { diffusivity }\left(\mathrm{cm}^{2} / \mathrm{s}\right) \\
& V=\text { Darcy velocity } \\
& \theta=\text { volumctric water content }\left(\mathrm{cm}^{3} \text { water } / \mathrm{cm}^{3}\right. \text { total) } \\
& \phi \quad=\text { porosity }\left(\mathrm{cm}^{3} \text { voids } / \mathrm{cm}^{3}\right. \text { total). }
\end{aligned}
$$

Diffusional flux of contaminants dissolved in liquids is estimated from Fick's First Law

$F=-\theta \tau D \vec{\nabla} C=-\theta D_{E} \vec{\nabla} C=-D_{i} \vec{\nabla} C$

where

$$
\begin{aligned}
D= & \text { tracer diffusion coefficient in water }\left(\mathrm{cm}^{2} / \mathrm{s}\right) \\
D_{\mathrm{E}}= & \text { effective diffusion coefficient (used in } \\
& \text { transport equation) }\left(\mathrm{cm}^{2} / \mathrm{s}\right) \\
D_{\mathrm{i}}= & \text { intrinsic diffusion coefficient (measured in } \\
& \text { steady state flux experiments) }\left(\mathrm{cm}^{2} / \mathrm{s}\right) \\
\tau= & \text { tortuosity factor. }
\end{aligned}
$$

If linear reversible sorption is assumed, Equation 2 reduces to

$\theta \frac{\partial C}{\partial t}=\frac{1}{R_{d}} \vec{\nabla} \cdot(\theta \tau D \vec{\nabla} C)-C \frac{\partial \theta}{\partial t}-\lambda \theta C$

where

$$
\begin{aligned}
& C=\text { concentration in liquid }\left(\mathrm{g} / \mathrm{cm}^{3}\right) \\
& \lambda=\text { decay constant }\left(\mathrm{s}^{-1}\right) \\
& D=\text { dispersivity }\left(\mathrm{cm}^{2} / \mathrm{s}\right) \\
& \rho_{b}=\text { bulk density }\left(\mathrm{g} / \mathrm{cm}^{3}\right)
\end{aligned}
$$

Discussion. There are several potential problems caused by a lack of standardization of nomenclature in the diffusion literature. Because the nomenclature used in the literature for the different types of diffusion coefficients is highly variable and inconsistent, we have attempted to apply a consistent nomenclature in this report as defined in Equation (10). Several different approaches found in the literature are discussed below.

The tortuosity factor can be expressed as

$$
\tau=\frac{\delta}{\tau_{o}^{2}}
$$

where

$$
\begin{aligned}
& \delta=\text { constrictivity } \\
& \tau_{0}=\text { tortuosity. }
\end{aligned}
$$

Since tortuosity and constrictivity corrections generally appear as a single lumped factor in experimental work, simplicity is maintained by using a single parameter $(\tau)$.

Atkinson and Nickerson (1988) define a capacity factor (a) and relate it to the distribution coefficient in the following manner:

$\alpha=\phi+(1-\phi) \gamma$,

which is equivalent to

$\alpha=\phi+(1-\phi) \rho_{s} K_{d}=\phi+\rho_{b} K_{d}=\phi R_{d}$.

The total concentration of contaminant in the concrete, assuming full liquid saturation, is

$C_{t}=\phi C_{l}+(1-\phi) C_{s}=C_{l} \alpha$.

Substituting into the diffusion Equation (11) the following is obtained

$\frac{\partial C_{t}}{\partial t}=\vec{\nabla} \cdot \frac{\phi \tau D}{\alpha} \vec{\nabla} C_{t}-\lambda C_{t}=\vec{\nabla} \cdot D_{a} \vec{\nabla} C_{1}-\lambda C_{t}$

where

$$
\begin{aligned}
D_{a}= & (D \tau \phi) / \alpha \\
\gamma= & \text { volumetric distribution coefficient } \\
& \text { (dimensionless) } \\
\rho_{s}= & \text { density of the solid }\left(\mathrm{g} / \mathrm{cm}^{3}\right) \\
\alpha= & \text { capacity factor (dimensionless). }
\end{aligned}
$$

Using, the Atkinson nomenclature the diffusional flux of contaminant can be expressed as

$F=D_{a} \vec{\nabla} C_{\imath}$

In Crank (1975), the diffusion equation with linear sorption is expressed as

$\frac{\phi \partial C_{t}}{\partial t}=\frac{1}{1+R} \vec{\nabla} \cdot \phi D \vec{\nabla} C$. 
If $(1+R)$ is replaced with $R_{d}$ and $D$ with $D_{E}$ in the above equation, then we have the form used in Equation (8).

It is very important to carefully define and understand the meaning of all the terms when applying the transport equation. Consistency must be maintained between the conventions used in the experimental determinations of diffusion coefficients and in the use of diffusion coefficients in performance assessments.

Experimental Diffusion Results. In the absence of radioactive decay, steady-state flux is independent of sorption. Sorption delays the time for attainment of steady-state, but does not impact steady-state flux. If radioactive decay is significant, then sorption will lower the steady-state flux.

Most diffusion coefficients obtained in the literature result from measurement of steady-state flux. The reported (intrinsic) diffusion coefficients lump the tracer diffusion cocfficient in water, the porosity, and tortuosity into one parameter. Atkinson et al. (1984) report laboratory and literature results for intrinsic diffusion coefficients as a function of the WCR. These results are fit to an equation of the form

$$
\log D_{i}=6 w c r-9.84
$$

or

$D_{i}=\phi \tau D=1.45 \cdot 10^{-10} \exp (13.8 w c r)$

where

$$
\begin{aligned}
& D_{i}=\text { intrinsic diffusion coefficient }\left(\mathrm{cm}^{2} / \mathrm{s}\right) \\
& \text { w.cr }=\text { water-to-cement ratio (by mass). }
\end{aligned}
$$

The results are illustrated in Figure 3. In the lower range of WCRs (0.2 to 0.44), characteristic of well-designed concrete enginecred barriers, the intrinsic diffusion coefficient ranges from $10^{-9}$ to $10^{-7} \mathrm{~cm}^{2} / \mathrm{s}$.

The porosity of concrete is dependent upon WCR, curing, and the porosity of the aggregate. Powers (1958) reports that the densest possible completely hydrated cement paste has a porosity of about $28 \%$. This occurs at a WCR of around $0.35-0.40$. Porosity lower than $28 \%$ in cement paste can only be generated by the presence of unhydrated cement.

Figure 4 illustrates the porosity data from Alford and Rahman (1981). The data has been fit to a curve of the form

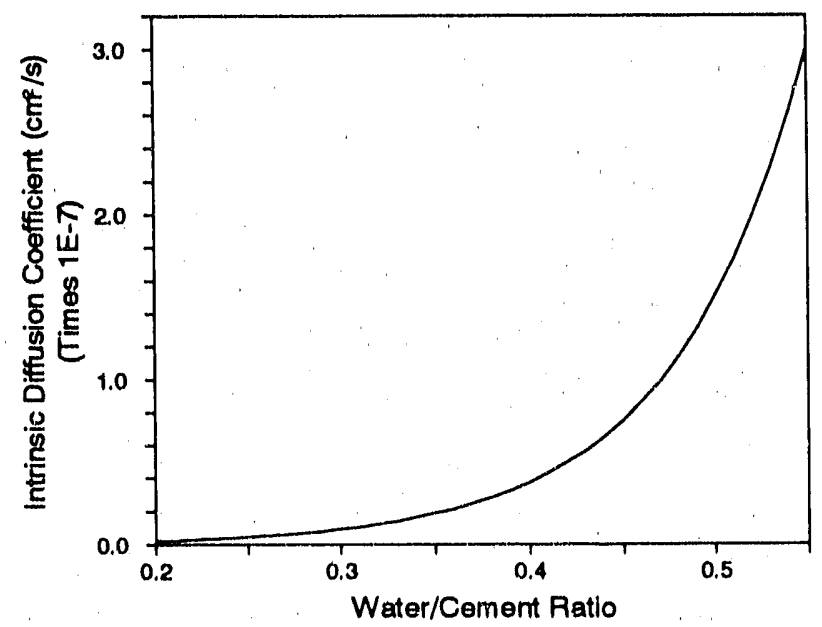

Figure 3. Intrinsic diffusion coefficient in cement paste as a function of WCR.

$\phi=0.61+0.23 \ln (w c r)$.

In the interest of generality, most reasearch on cement properties is performed with crment past in the absence of aggregate. When examining the literatuie on concrete and when preparing performance assessment calculations, one must be careful to distinguish between the two. Generally about $60-75 \%$ by volume of concrete is aggregate.

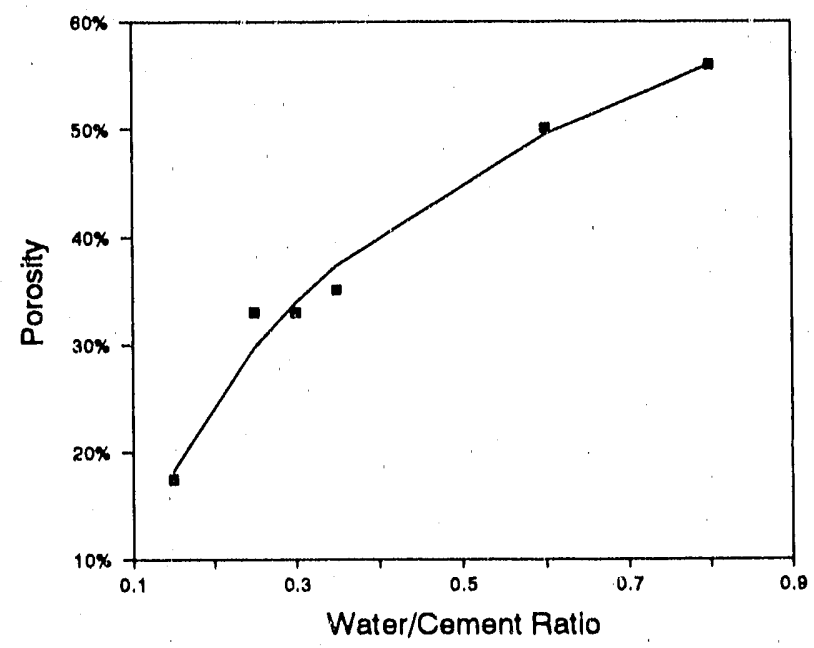

Figure 4. Relation between WCR and porosity.

The decomposition of measured diffusivity into individual components of porosity, tortuosity, and diffusion coefficient in water becomes important when transient diffusional processes are considered. Transient diffusional fronts move more rapidly when the tortuosity factor is high. Thus, a low tortuosity factor is favorable for waste isolation. Combination of the empirical relationships for porosity of cement and effective diffusivity gives an estimate of tortuosity factor as a function of WCR. 


$$
\begin{aligned}
\tau & =\frac{D_{i}}{D \phi}=\frac{1.45 \cdot 10^{-10} \exp (13.8 w c)}{(0.61+0.23 \ln (w c)) 10^{-5}} \\
& =\frac{0.00145 \exp (13.8 w c r)}{61+23 \ln (w c r)}
\end{aligned}
$$

The estimated tortuosity factor is illustrated in Figure 5. Note that the tortuosity factor declines with lower WCR. Thus, a lower WCR tends to slow transient diffusion rates and gives increased contaminant residence times as well as slow steady-state diffusional transport.

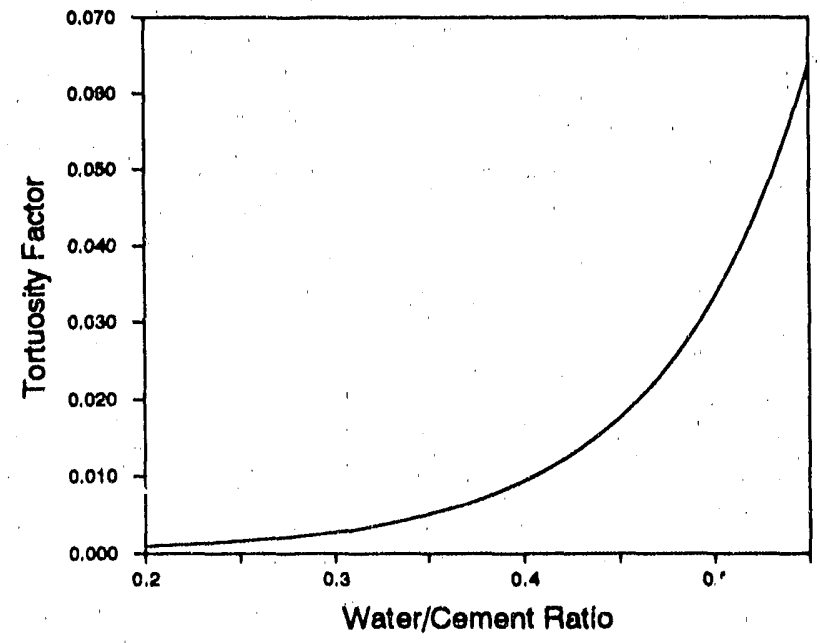

Figure 5. Estimated tortuosity factor for cement as a function of WCR. 


\section{SULFATE AND MAGNESIUM ATTACK}

\section{Sources of Sulfur and Magnesium}

Sulfur. Sulfur generally occurs in the fully oxidized $\left(\mathrm{S}^{6+}\right)$ state when dissolved in water and is combined with oxygen as sulfate $\left(\mathrm{SO}_{4}{ }^{2}\right)$ ion. The reduced form of sulfur, sulfide $\left(\mathrm{S}^{2}\right)$ occurs as the bisulfide ion (HS) or undissociated $\mathrm{H}_{2} \mathrm{~S}$ in most soil water solutions, although the $\mathrm{S}^{2}$ form may occur at the high $\mathrm{pH}$ of concrete. Conversion to and from the oxidized state is often associated with biochemical processes. Because of the slowness of sulfur oxidation or reduction reactions, nonequilibrium forms of sulfur can persist for long periods ( $\mathrm{Icm}, 1970)$.

Sulfur is not a major constituent of the earth's crust, but is widely distributed in igncous and sedimentary rocks as metal sulfides. Weathering in contact with oxygenated water results in oxidation leading to the formation of sulfate ions. Sulfate occurs in certain igncous-rock minerals of the fieldspathoid group, but the most extensive occurrences are in evaporite deposits. Calcium sulfate as gypsum, $\mathrm{CaSO}_{4} 2 \mathrm{H}_{2} \mathrm{O}$, or as anhydrite, which contains no water of crystallization, makes up a considerable part of many cvaporite-rock sequences (I Iem, 197()).

The second source of sulfate is from precipitation. At Ilubbard Brook, Now Ilampshire, an extensively studied watershed, sulfale inputs exeecd outpuls indicating net accumulation of sulfate in the ccosystem (Likens et al., 1977).

Sulfate concentrations are increased in arid regions by evapotranspiration. This is especially important in regions where potential evapotranspiration exceeds precipitation.

Magnesium. The magnesium ion $\left(\mathrm{Mg}^{2+}\right)$ is normally the predominant form of magnesium in solution in natural water. The complex $\mathrm{MgOII}^{+}$will be significant at $\mathrm{pH}>10.0$ (IIcm, i970).

In igncous rock, magnesium is typically a constituen of the ferromagnesian mincrals. These include olivine, pyroxenes, amphiboles, and dark-colored micas. In metamorphic rocks, magnesian mineral species such as chlorite, montmorillonite, and serpentine occur. Sedimentary forms of magnesium include carbonates such as magnesite and hydromagnesite, brucite, and dolomite (IIem, 1970). Studies at Ilubbard Brook indicate that output of magnesium consistently excecds input from precipitation (Likens et al., 1977).

Magnesium may be added to sites in the form of dust suppressants such as $\mathrm{MgCl}_{2}$ during or after construction.

\section{Sulfate and Magnesium Attack}

Sulfate reacts with tri-calcium aluminate $\left(C_{3} A\right)$ to form calcium aluminum sulfates leading to expansion and disruption of the cement. A related problem is the reaction of magnesium with the cement to form Brucite $\left[\mathrm{Mg}(\mathrm{OH})_{2}\right]$.

Sulfate ions migrate into the concrete and react with the cement paste, forming gypsum and calcium sulphoaluminate. The products of the reaction have considerably greater volume than the compounds they replace, so that the reactions with the sulfates lead to expansion and disruption of the concrete. The reaction of sulfate with portlanditc $\left[\mathrm{Ca}(\mathrm{OH})_{2}\right]$ to form gypsum, monosulphoalum inate, and ettringite can be written as

Gypsum:

$$
\begin{array}{r}
\mathrm{Ca}(\mathrm{OH})_{2}+\mathrm{SO}_{4}^{2-}+2 \mathrm{H}_{2} \mathrm{O} \Rightarrow \\
\mathrm{CaSO}_{4} \cdot 2 \mathrm{H}_{2} \mathrm{O}+2 \mathrm{OH}^{-}
\end{array}
$$

Monosulphoaluminate:

$$
\begin{gathered}
3 \mathrm{CaO} \cdot \mathrm{Al}_{2} \mathrm{O}_{3} \cdot 6 \mathrm{H}_{2} \mathrm{O}+\mathrm{CaSO}_{4}+6 \mathrm{H}_{2} \mathrm{O} \Rightarrow \\
3 \mathrm{CaO} \cdot \mathrm{Al}_{2} \mathrm{O}_{3}\left(\mathrm{CaSO}_{4}\right) \cdot 12 \mathrm{H}_{2} \mathrm{O}
\end{gathered}
$$

Ettringitc:

$$
\begin{gathered}
3 \mathrm{CaO} \cdot \mathrm{Al}_{2} \mathrm{O}_{3}\left(\mathrm{CaSO}_{4}\right) \cdot 12 \mathrm{H}_{2} \mathrm{O}+2 \mathrm{CaSO}_{4}+2 \mathrm{H}_{2} \mathrm{O} \Rightarrow \\
3 \mathrm{CaO} \cdot \mathrm{Al}_{2} \mathrm{O}_{3} \cdot 3\left(\mathrm{CaSO} \mathrm{CaS}_{4}\right) \cdot 32 \mathrm{H}_{2} \mathrm{O} .
\end{gathered}
$$

Studies on the behavior of concrete in sulfate soils (Stark, 1982) indicate that the WCR with its attendant impact upon porosity and permeability is the single most important factor affecting resistance to sulfate altack. $\mathrm{C}_{3} \mathrm{~A}$ content of the cement also significantly affects concrete durability in sulfate environments with a low $\mathrm{C}_{3} \mathrm{~A}$ content, leading to greater resistance to sulfate attack. Studies at the PCA (Klicger, 1980) indicated that the rate of sulfate attack in high sulfate soils was approximately proportional to $C_{3} A$ content. Type $V$ cement had a lifetime about 2-3 times as long as Type I cement. Performance had a greater dependence upon WCR than $\mathrm{C}_{3} \mathrm{~A}$ content. Moving from four bag to seven bag cement resulted in a 10-20 fold increase in lifctime.

An example of the reaction of cement paste with magnesium sulfate (Neville, 1981, is

$$
\begin{aligned}
& 3 \mathrm{CaO} \cdot 2 \mathrm{SiC}_{2}+3 \mathrm{MgSO}_{4} \cdot 7 \mathrm{H}_{2} \mathrm{O} \Rightarrow \\
& \quad 3 \mathrm{CaSO}_{4} \cdot 2 \mathrm{H}_{2} \mathrm{O}+3 \mathrm{Mg}(\mathrm{OH})_{2}+2 \mathrm{SiO}_{2} .
\end{aligned}
$$


The low solubillty of $\mathrm{Mg}(\mathrm{OHI})_{2}$ causes the reaction to procesd to completion, making the altack more severe. Further reaction between $\mathrm{Mg}(\mathrm{OII})_{2}$ and sllica gel is possible and may also cause deterioration.

\section{Models of Sulfate and Magnesium Attack}

Limpirical ( $\Lambda$ tkinson and Ilcarnc, 1984 and Atkinson $e$ al., 1985), shrinking core mechanistic models (Rasmuson et al, 1987), and more complete mechinistic models (Alkinson and Ilearne, 1990) have been appliad.

An empirically derived relation for sulfate attack was developed by Aikinson and Heame (1984). Data collected in the Northwick lark study (larrison and Teychenne, 1981) was used to develop the empirical model. The logic was as follows; The observed loss of cement at the comers of the blocks after 5 years in $0.19 \mathrm{M} \mathrm{Na}_{2} \mathrm{SO}_{4}$ solution was $42 \mathrm{~mm}$. The cube experiments indicated that the depth of attack was linear with time. It was assumed that the rate of attack is proportional to sulfate concentration in the solution and tricalciumaluminate content of the cement. The depth of allack in $\mathrm{MgSO}_{4}$ solution was approximately twice that in $\mathrm{Na}_{2} \mathrm{SO}_{4}$. Ordinary Portland Cement (OP') with $8 \% \mathrm{C}_{3} \mathrm{~A}$ had the greillest effects and was used as a reference material. These assumptions lead to the following equation

$$
\begin{aligned}
x & =\frac{4.2}{5} \frac{\mathrm{C}_{s}}{8} \frac{\left(\mathrm{Mg}^{2+}+\mathrm{SO}_{4}^{2-}\right)}{0.19} t \\
& =0.55 \mathrm{C}_{4}\left(\mathrm{Mg}^{2+}+S \mathrm{SO}_{4}^{2-}\right) t
\end{aligned}
$$

where

$$
\begin{aligned}
& \mathrm{x}=\text { depth of deterioration }(\mathrm{cm}) \\
& \mathrm{C}_{3}=\text { weight percent of } \mathrm{C}_{3} \mathrm{~A} \text { in unhydrated cement } \\
& \left.\mathrm{Mg}^{2+}, \mathrm{SO}_{4}{ }^{\prime}=\text { concentration in bulk solution (mole } / 1\right) \\
& \mathrm{t}=\mathrm{time}(\mathrm{yr}) .
\end{aligned}
$$

A modified version of this empirical model is used in the Barrier code (Shuman et al., 1989)

$x=1.86 \cdot 10^{6} \mathrm{C}_{s}\left(\mathrm{Mg}^{2+}+\mathrm{SO}_{4}^{2-}\right) \mathrm{D}_{i} t$

where

$$
\begin{aligned}
D_{1}= & \text { intrinsic diffusion coefficient in concretc } \\
& \left(\mathrm{cm}^{2} / \mathrm{s}\right) \text {. }
\end{aligned}
$$

This relationship can be derived from Equation (1) by introducing the further assumptions that (a) the intrinsic diffusion coefficient in the experimental concrete blocks was $3 \times 10^{-7} \mathrm{~cm}^{2} / \mathrm{s}$ and (b) the ralc of altack is proportional to the dilfusion coeflicient.

Empirical correlations have obvious limitations, expecially when applied outside the range of the basis data. Correlations are only valid over the range of the time/system paramelers tested. Applicalion outside of this range is highly questionable. The empirical correlation does not include the impacts of advective transport and/or the known importance of WCR on durability. Application of the empirical model is not clcarly conservative. Notwithstanding these limitations, the simple empirical model is frequently the best option avallable for estimating resistance to sulfate attack (Figure 6).

\section{Sulfate Transport}

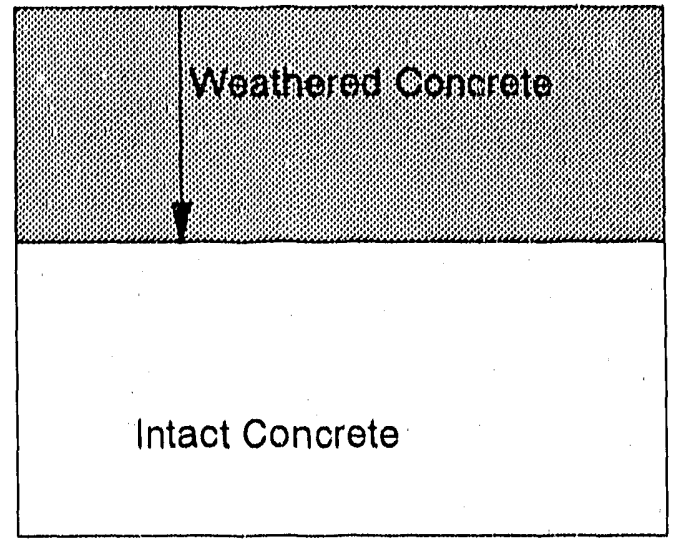

Figure 6. Schematic of sulfate attack.

Shrinking Core Model. Shrinking core models have been used in chemical engineering where a moving boundary condition exists, but the rate of movement of the boundary is slow relative to transport rates. Because of the slow movement of the houndary, the mass transport processes can be considered to be always near steady state. This assumption is sometimes referred to as a series of stationary states.

In the case of sulfate attack, envision that sulfate ions migrate inward through weathered concrete to the boundary with intact, unweathered material. At the interface, the sulfate ions react with hydration products of tricalcium aluminate forming insoluble solids (e.g., ettringite). The mass transport equations are assumed to be always at steady state and are then used to estimate the rate of movement of the weathering zone into the concrete. The reactions are simplistically reduced to the format

$\mathrm{SO}_{4}^{2-}+\mathrm{X}^{2+} \Rightarrow \mathrm{XSO}_{4}^{2-}$.

The flux of sulfate ions is given as

$N=-D_{i} \frac{C_{0}}{x}$.

The rate of movement of the weathering zone is then the rate of mass transport divided by the concentration of tricalcium aluminate in the solid 
$\frac{d x}{d t}=-\frac{N}{C_{s}}=\frac{D_{1} C_{o}}{C_{s} x}$

$x=\left(\frac{2 D_{1} C_{0}}{C_{s}} t\right)^{\frac{1}{2}}$

where

$C_{1}=$ concentration of tricalcium aluminate in the solld (molcs $/ \mathrm{cm}^{3}$ )

$\mathrm{C}_{0}=$ concentration of sulfate in the bulk solution (moles $\left./ \mathrm{cm}^{3}\right)$

$x=\operatorname{distance}(\mathrm{cm})$

$D_{1}=$ intrinsic diffusion cocfficient $\left(\mathrm{cm}^{2} / \mathrm{s}\right)$

$\mathrm{N}=\operatorname{molar}$ flux $\left[\mathrm{molcs} /\left(\mathrm{cm}^{2} \mathrm{~s}\right)\right]$

$t=t \mathrm{me}(\mathrm{s})$.

A more rigorous mathemalical solution of the same problem, considering a full set of chemical reactions and rigorous solution of the mass transport cquations, has also been applied to the problem (Rasmuson et al., 1987) and gave sim ilar results to the shrinking core model. The actual ratio of sulfalt to $C_{3} \Lambda$ is variable. For simplicity, a 1:1 ratio was assumed in the derivation.

Examination of the two formulac for sulfate attack (or taking derivatives) indicates that the impact of the $\mathrm{C}_{3} \mathrm{~A}$ content of the cement differs not only in magnitude but in sign. The empirical model predicts that sulfate attack rate will increase with increasing $\mathrm{C}_{3} \mathrm{~A}$ content while the shrinking core model predicts that the attack rate will decrease with increasing $\mathrm{C}_{3} \wedge$ conlent of the cement. Thus, the shrinking core model is in direct conflict with experimental data and field experience with sulfale attack.

A second problem with the shrinking core or simple mass transport limitation to sulfate attack is that it predicts a square root of time dependence of the altack rate, whereas experimental dilla are consistent with a constant rate of altack.

Mechanistic Model. Atkinson and llarne (1990) developed a mechanistic model for sulfate attack. The model considers sulfate at tack as a three step process:

1. Sulfate tons penetrate the concrete, usually by diffusion

2. Sulfate ions react expansively with aluminium contulning phases in the concretc

3. The resulling internal expansion caluses stress, cracking, and exfoliation of concrete from the surface.

The process is dependent upon concrete composition, mass transport rates, and reaction rates. Reaction kinetics are estimated by $\begin{array}{ll}m=m_{o} \log _{10}\left(\frac{t_{\text {spall }} c_{0}}{t_{r} c_{k}}\right) & m<m_{c} \\ m=m_{c} & m>m_{c} .\end{array}$

The concentration of reacted sulfate as ettringite $\left(\mathrm{C}_{\mathrm{E}}\right)$ is given as

$C_{E}=m \cdot\left(\frac{\text { mass cement }}{\text { volume concrete }}\right)$

The thickness of a layer that spalls off is given by

$X_{\text {spall }}=\frac{2 \alpha j(1-v)}{E\left(B C_{E}\right)^{2}}$.

The tine for the layer to spall is given by

$t_{\text {spall }}=\frac{X_{\text {spall }}^{2} C_{E}}{2 D_{l} c_{0}}$

The degradation rate is given as

$R=\frac{X_{\text {spall }}}{t_{\text {sprall }}}=\frac{E \mathrm{~B}^{2} c_{0} C_{E} D_{i}}{\alpha \gamma(1-v)}$

Depending upon the rate of diffusion relative to reaction rates, some iteration may be required to determ ine the proper value for $\mathrm{C}_{\mathrm{g}}$.

where

$c_{k}=$ sulfate concentration in kinetic experiments $\left(\mathrm{mol} / \mathrm{m}^{3}\right)$

$c_{0}=$ sulfate concentration in bulk solution $\left(\mathrm{mol} / \mathrm{m}^{3}\right)$

$\mathrm{C}_{\mathrm{E}}=$ concentration of reacted sulfate as ettringite $\left(\mathrm{mol} / \mathrm{m}^{3}\right)$

$D_{1}=$ intrinsic diffusion cocfficient $\left(\mathrm{m}^{2} / \mathrm{s}\right)$

$\mathrm{E}=$ Young's modulus (20 GPa)

$\mathrm{m}=$ quantity of sulfate reacted with cement ( $\mathrm{mol} / \mathrm{kg}$ ankydrous sement)

$m_{c}=$ valuc of $\mathrm{m}$ for compirte reaction (mol $/ \mathrm{kg}$ anhydrous cement)

1.24 for OPC and 1.07 for Sulfate Resistant Portland Cement (SRPC)

$m_{0}=$ kinetic constant for $m$ 0.32 for OPC and 0.16 for SRPC

$\mathrm{R}=$ concrete degradation ratc $(\mathrm{m} / \mathrm{s})$

$\mathrm{t}_{\mathrm{r}}=$ characteristic time for reaction (s) 3577 for OPC and 1555 for SRPC

$\alpha=$ roughness factor for fracture path (assumed to be 1.0)

$\mathrm{B}=$ linear strain caused by one mole of sulfate reacted in $1 \mathrm{~m}^{3}\left(1.8 \times 10^{-6} \mathrm{~m}^{3} / \mathrm{mol}\right)$

$\gamma=$ fracture surface energy of concrete $\left(10 \mathrm{~J} / \mathrm{m}^{-2}\right)$

$v=$ Poisson's ratio $(0,3)$. 
In the example calculations given by Aikinson and Hearne (1990), the rate of attack for the sulfate resistant portland cement (SRPC) was approximalely $30 \%$ lower than the attack rate for ordinary portland cement (OPC). This suggests that WCR (as reflected in the intrinsic diffusion cocfficient) will be more important in controlling sulfate attack than the chemical composition of the cement. The importance of WCR in the mechanistie model is consistent with the observed importance of WCR in sulfate attack (Klieger, 1980).

\section{Example Calculations}

A few example calculations fllustrate the types of concrete longevily predictions expected from the models for sulfate altack. Figures 7 through 9 represent predictions from the empirical model for sulfate altack. These graphs represent three different water chemistries that typify soil ehemistry from around the Uniled Stales. The different water chemistries are nominally labeled as northeast, midwest, and southwest locations. Actual performance calculattons should ullize sitc specific chemical parameters; these calculations are only intended as illustrations.

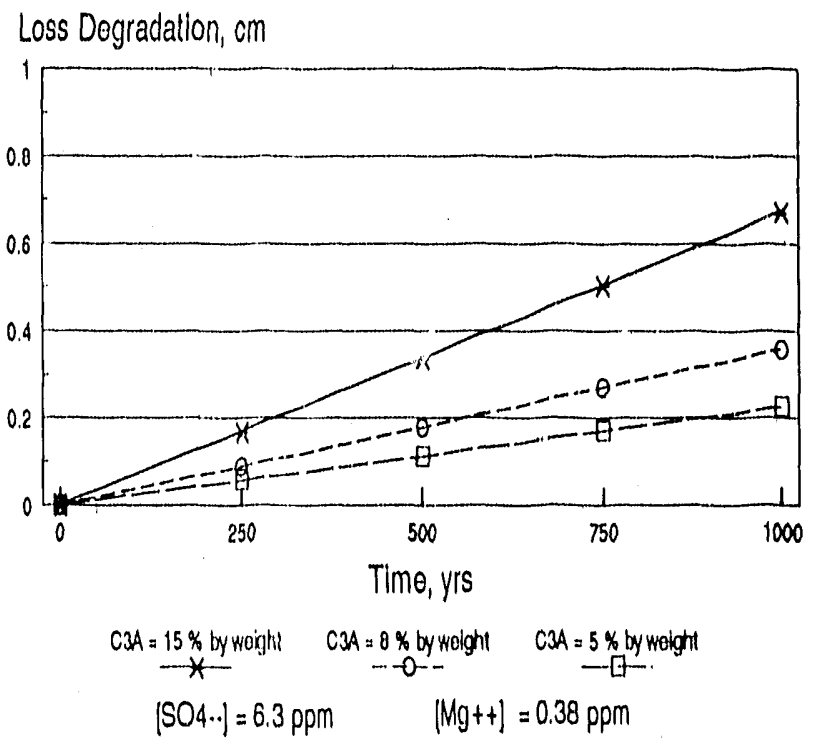

Figure 7. Listimates of sulfale attack in a low sulfate environment based upon empirical model.

The empirical model suggests that, from a standpoint of sulfate altack, concrete barriers will be much more effective in humid climaltes where sulfate levels are lower. I Iowever, the data upon that the empirical model is based do not incluele a situation where the water is forced to flow through the concrete (c.g, the siluation with the roof of a concrete vaull).
Results from the mechanistic model of Atkinson and Hleame (1990) are given in Figure 10. The graph is based upon the measurements for OPC and SRPC made in laboral ory experiments. Becaluse of the limited amount of data a allable for parameterization of the mechanistic model, it is difficult to directly compare empirical and mechanistic model predictions. The diffusion coefficient and the sulfate concentration are the most significant factors Influencing resistance to sulfate at tack, even more important than the type of concrete. High qualily concrete with a low WCR will have a low diffusion cocfficient ieading to erihanced sulfate resistance.

\section{Loss Degradallon, om}

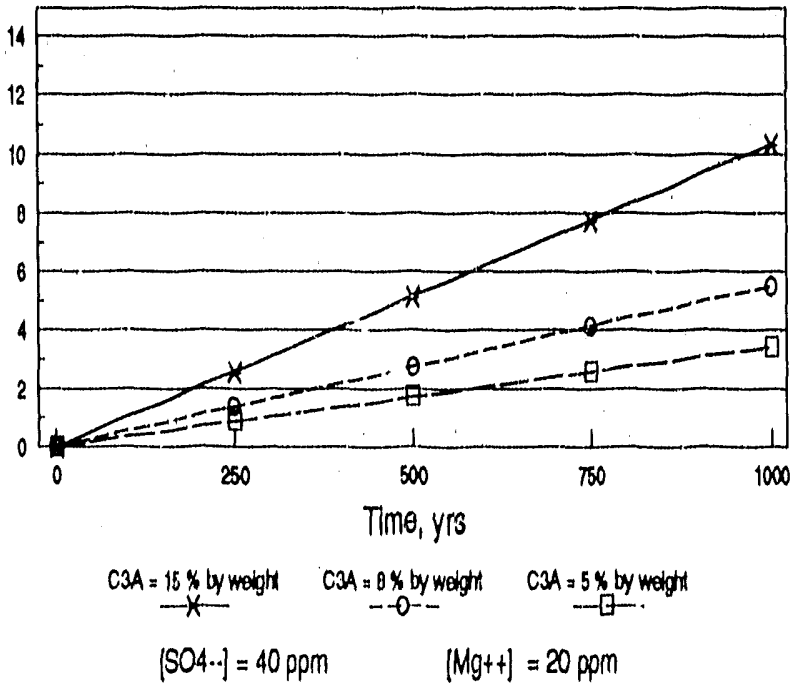

Figure 8. Estimates of sulfate attack rate in a midrange sulfute environment based upon empirical model.

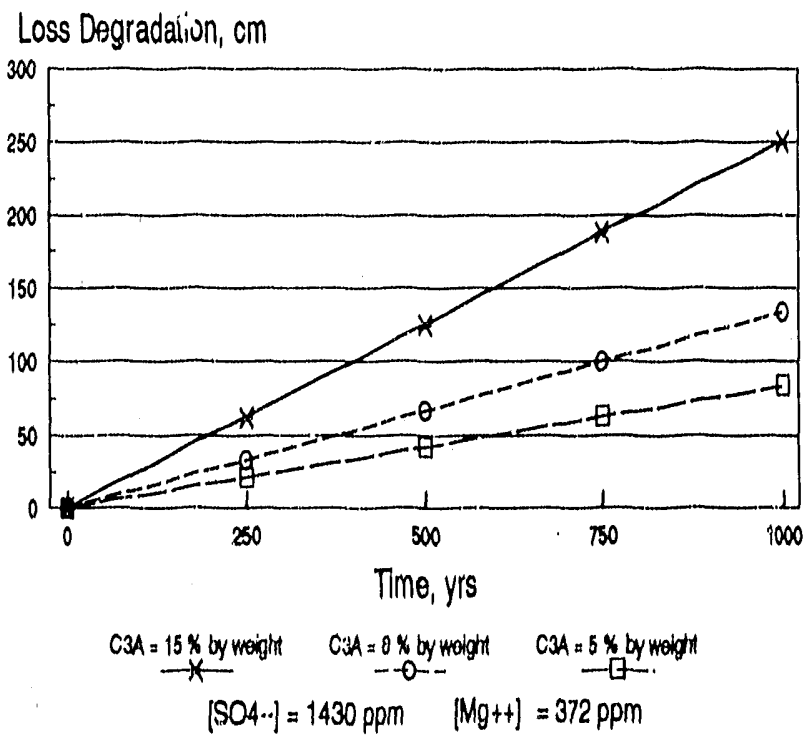

Figure 9. Estimates of sulfate attack rate in a high sulfate enviroriment based upon empirical mociel. 


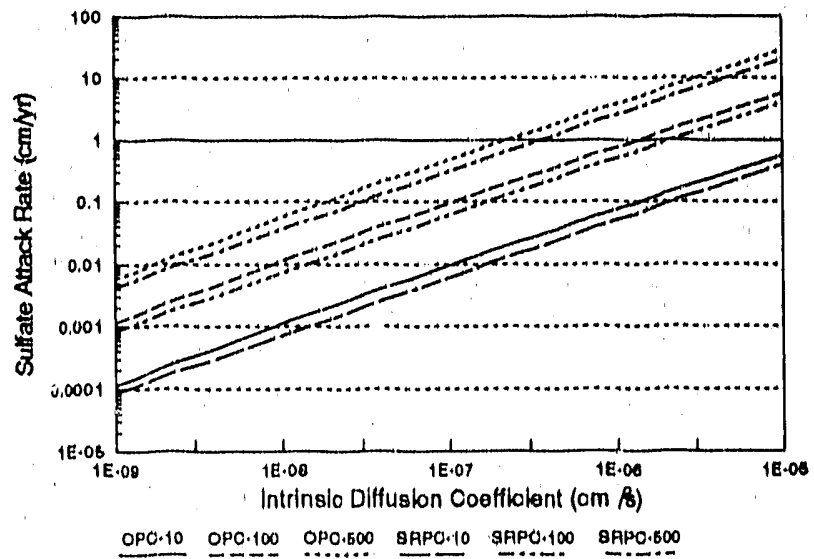

Figure 10. Estimates of sulfate attack rate based upon mechanistlc model of sulfate attack. The lines represent calculations for OPC and SRPC at sulfate concentrations of 10,100 , and $500 \mathrm{ppm}$. 


\section{REINFORCEMENT CORROSION/CHLORIDE ATTACK}

\section{Reinforcement Corrosion}

Sted relinforcement is usul in concrete construction because the properties of the two materials are complementary. Stecl has a very high tensile strength but less resistance to compressive stress. Concrete has low tensile strength but high compressive strergth and is relatively inexpensive. These propertles nave led to wldespread use of reinforced concrele beams and slabs.

The alkallne environment inside the concrete and isolation from external corrosive agents such as oxygen and chloride protect the sted reinforcement from corrosion by forming a protective oxide layer on the netal surface (Figure 11). As the concrele deleriorates and is subject to ingression of corrosive agents, the passive layer may undergo attack leading to active metal corroston. Corrosion of the stecl reinforcement, which oecurs upon brcakup of the passive layer, is important both from a structural standpoint and because corrosion can lead to concrete cracking.

Cracking of the concrete is calused becaluse corrosion of stecl results in corrosion products that significantly increase its molar volume. An example of the influence of different steel corrosion products upon volume taken from Walton and Sagar (1987) is given in Table 3. Exparsiston of the stcel leads to spalling and disruption of the concrete. Reinforcement corrosion also lowers the strength of the stcel, leading to potcnllal structural instabilitics.

The methodology for determining when reinforcement corrosion caluses additional cracking is nol straightforward. Loss of stecl causes increased strain from physical loads on the structure. Additionally, the concrete can be expected to crack over the sleel when the internal pressure generated by the corrosion products exceeds the tensille strength of the concrete.

Table 3. Volume changes resulting from stecl corrosion.

\begin{tabular}{lcc}
\hline Corrosion Products & $\begin{array}{c}\text { Molar Volume } \\
\left(\mathrm{cm}^{3} / \text { mole }\right)\end{array}$ & $\begin{array}{c}\text { Proportional } \\
\text { Volume } \\
\text { Increase }\end{array}$ \\
\hline Iron (fie) & 7.09 & - \\
Magnetile $\left(\mathrm{Fe}_{3} \mathrm{O}_{4}\right)$ & 44.5 & 2.1 \\
Iron Sulfide $(\mathrm{FeS})$ & 17.6 & 2.5 \\
Siderite $\left(\mathrm{FeCO}_{3}\right)$ & 29.4 & 4.2 \\
\hline
\end{tabular}

Breakup of the passive layer has historically been assoclated with the ingress of chloride lons into the concrete (ACI, 1985). Elevated levels of chloride lead to destruction of the passive layer because of specific attack or by serving as a supporting electrolyte in the solution. Chlorides are particularly important in concrete bridge decks where salt is added for deicing (Clear, 1976). The start of reinforcement corrosion is thought to be associated with a critical or threshold chloride level. Clear (1976) gives the chloride threshold as 0.02 mass percent of the cement paste. Subramanian and Wheat (1989) give the critical threshold level for chlorides in the pore solution as approximately 700 ppm. Recent work (Yonezawa et al., 1988) has evaluated the importance of good adhesion between steel and mortar as being of equal importance in influencing the start of corrosion in chloride solutions.

In the absence of elevated levels of chloride, reinforcement corrosion may begin when the alkalinity of the concrete is reduced, making the passive layer less stable. Processes such as carbonation and leaching lead to a gradual lowering of pH in concrete with eventual loss of passivity. Depassivation of the steel reinforcement can occur when the pH near the bars drops below 9 (Papadakis et al., 1989). Chloride attack predominates in marine or coastal environments or where deicing salts are applied to the concrete. Depassivation by lowering the concrete $\mathrm{pH}$ through carbonation or leaching may be more important in low chloride environments.
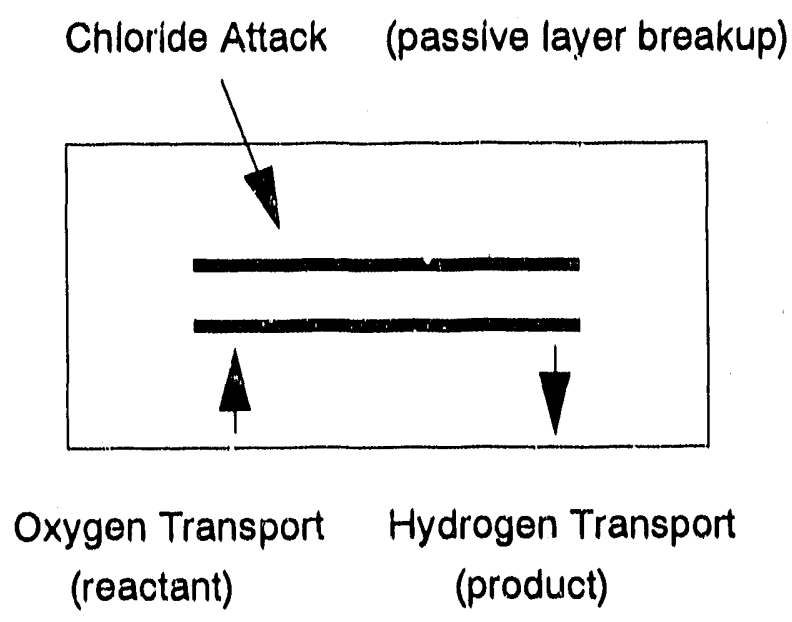

$$
\text { Corrosion } \Rightarrow>\text { Expansion } \Rightarrow>\text { Cracking }
$$

Figure 11. Schematic of chloride attack on stcel reinforcement. 
Studies of stecl corrosion in concrete slabs (Clear, 1976) clearly established that WCR and depth of cover over the reinforcement are the most important parameters affecting time until depasssivation.

\section{Sources of Chloride}

Chloride is present as the chloride ion ( $\left.\mathrm{Cl}^{\circ}\right)$. In most soil environments, chloride acts as a conservattve ton with relatively few chemical reactions.

Chlordde is present in igneous rocks in lower concentrations than any of the other major constituents of natural water. Sedimentary rocks, particularly the cvaporiles, contaln higher chloride levels (Hem, 1970).

Precipitation close to the occans commonly contains from $1 \mathrm{mg} / 1$ to several tens of $\mathrm{mg} / \mathrm{l}$ of chloride, but the concentrations observed generally decrease rapidly in a landward direction.

Studics at Lubbard Brook, New Hampshire (Likens et al., 1977), indicale that chloride in this humid northern location is nearly at balance (1.e., input $=$ output).

In arid regions, soil concentrations of chloride may be greatly elevated as a result of evaporation.

Chloride may be added to surfaces as a deicer and/or dust suppressant during construction or operation of the site.

\section{Models of Chloride Attack}

Chloride attack is modeled as a two stage process (a) time to breakup of the passive layer and initiation of corrosion and (b) corrosion ratte subsequent to breakup of the passive layser.

Initiation. An empirical correlation for time to depassivation developed by Stratful and modified by Clear (1976) is

$$
t_{c}=\frac{129 x_{c}^{1.22}}{(W C R)[C l]^{0.42}}
$$

where

$$
\begin{aligned}
t_{c}= & \text { time to onset of corrosion (yr) } \\
x_{c}= & \text { thickncss of concrete over the rebar (in.) } \\
\mathrm{WCR}= & \text { water to cement ratio (by mass) } \\
\mathrm{Cl}= & \text { chloride ion concentration in groundwater } \\
& \text { (ppm). }
\end{aligned}
$$

The empirical equation clearly illustrates the impacts of cover over the sted and " $/ \mathrm{CR}$ on protection of the steel. The empirical model of Clear is used in the Barrier code (Shuman et al., 1989).
A more complete mechenistic description of the problem ts given by Pazant (1979a; 1979b). Bazant derives the governing equations for transport of chloride, oxygen, and water through the concrete. Subramanlan and Wheat (1988) give the results of a one dimensional solution of Bazant's corrosion model.

An alternative for estimating the time to initiation of corrosion is to solve the mass transport equation for the arrival time of chloride. When the critical chloride level is reached at the depth of the reinforcement, breakup of the passive layer can be assumed to initiate.

The governing equation considering diffusion only transport can be given as

$$
\frac{C-C_{i n t}}{C_{B w}-C_{l n t}}=\operatorname{ercf}\left(\frac{X}{\left(\frac{\Delta D_{t^{t}}}{R_{d}}\right)^{\frac{1}{2}}}\right)
$$

where

$$
\begin{aligned}
& C=\text { critical chloride concentration for inttiation of } \\
& C_{l n i}=\text { initial chloride concentration in concrete pore } \\
& \text { water } \\
& C_{g w}=\text { chloride concentration in the surrounding } \\
& \text { material } \\
& X=\text { depth of coyer over reinforcement. }
\end{aligned}
$$

The equation can be solved iteratively to obtain the time when the critical chloride threshold is reached at the level of the reinforcement.

Note that Equation (1), the empirical model, contains no pruvision for a chloride threshold - a serious but presumably conservative limitation. Equation (1) was derived from work related to bridge decks where salt is frequently applied for deicing. Application of the empirical equation to chloride concentrations typical of soils is clearly outside the range of the basis experimental data.

Simplified Corrosion Rate Calculation. The simpliest method for estimating the corrosion rate subsequent to initiation of corrosion is a one dimensional diffusion calculation assuming limitation of the corrosion rate by oxygen diffusion.

The overall reaction is described by an equation such as

$$
\mathrm{Fe}+\frac{3}{2} \mathrm{H}_{2} \mathrm{O}+\frac{3}{4} \mathrm{O}_{2}=\mathrm{Fe}(\mathrm{OH})_{3} \text {. }
$$

The flux of oxygen from the surface of the concrete to the level of the reinforcement is given by

$$
N_{O_{2}}=-D_{1} \frac{C_{s w}}{\Delta X} \text {. }
$$

The resulting corrosion rate is then 


$$
\begin{aligned}
R_{\text {corrarlat }} & =\frac{4}{3} N_{O_{2}} \frac{M_{F_{e}}}{\rho_{F_{e}}} \\
& \approx 9.4\left(\frac{\mathrm{cm}^{3}}{\text { mole }}\right) D_{1} \frac{C_{g w}}{\Delta X}
\end{aligned}
$$

The amount of reinforcement per unit area of concrete is

$\frac{\pi d^{2}}{4 s}$.

The percent of reinforcement remaining at any time is

$$
\% \text { remaining }=100\left(1-\frac{4^{*} 9.4\left(\frac{\mathrm{cm}^{3}}{m l_{l}}\right) s D_{l} C_{\mathrm{gw}} t}{\pi d^{2} \Delta X}\right)
$$

where

$$
\begin{aligned}
\Delta X= & \text { depth of reinforcement below surfice. } \\
M_{F e}= & \text { molccular weight of iron } \\
\rho_{F e}= & \text { density of reinforcement bars } \\
C_{g w}= & \text { concentration of oxygen in surrounding } \\
& \text { groundwater } \\
\mathrm{d}= & \text { diameter of reinforrement } \\
\mathrm{s}= & \text { spacing between reinforcement bars. }
\end{aligned}
$$

In the Barrier code, a one dimensional steady state equation for the diffusion of oxygen is used with a zero concentration boundary condition at the metal surface. This type of calculation gives an upper bound to the contribution of oxygen reduction in saturated concrete. However clevated transport rates of gases in partially saturated concrete, advective transport, and/or the impact of the hydrogen evolution reaction are not considered.

Complex Models. Computer codes and models developed to evaluate container corrosion in radioactive waste repositories are also applicable to prediction of the corrosion rate of stecl reinforcement. Harker et al., (1987) developed a one dimensional model for active corrosion of waste containers in concrete. Walton and Sagar (1987 and 1988) developed a general two dimensional model for active corrosion of stecl in mulliple layered geologic materials.

The models for active corrosion of steel assume that different combinations of mass transport and/or kinetics are rate limiting. In order to support oxidation of the steel through the reaction,

$\mathrm{Fe}(\mathrm{s}) \Leftrightarrow \mathrm{Fe}^{2+}+2 \mathrm{c}^{+}$,

an oxidizing agent must be present. The oxidizing agents most appropriate for a concrete environment are oxy gen gas and water. The kinetics of the oxygen reduction reaction can either be assumed to be transport limited or approximated with Butler-Volmer kinetics.

$\mathrm{O}_{2}(\mathrm{aq})+2 \mathrm{II}_{2} \mathrm{O}+4 \mathrm{e}^{*} \Rightarrow 40 \mathrm{OI}(\mathrm{aq})$.
An example of an kinetic equation for the oxygen reduction reaction is (Turnbull, 1980)

$i_{O_{2}}=k O_{2} \exp \left(\frac{\alpha F E}{R T}\right)$

$$
\begin{aligned}
k & =-4.9 \times 10-3 \mathrm{~A} / \mathrm{dm} / \mathrm{mole} \\
\alpha & =-0.5 .
\end{aligned}
$$

Because water is always available in a subsurface concrete environment and the overall reaction is favorable, the rate of the water reduction reaction must be estimated using kinetic expressions.

$\mathrm{H}_{2} \mathrm{O}+\mathrm{e}^{\cdot} \Leftrightarrow 0.5 \mathrm{H}_{2}(\mathrm{aq})+\mathrm{OH}(\mathrm{aq})$

The Butler-Volmer equation written for this reaction is

$$
\begin{gathered}
E_{e q}=-2.303 \frac{R T}{F}\left\{p H+0.5 \log \left[H_{2}(g)\right]\right\} \\
k=9.35 \times 10^{-10} \exp \left\{\frac{\alpha_{c} F E_{\text {eq }}}{R T}\right\} \\
i_{H_{2} O}=k\left[-\exp \left\{\frac{\alpha_{c} F}{R T}\left(E-E_{e q}\right)\right\}+\exp \left\{\frac{\alpha_{a} F}{R T}\left(E-E_{e q}\right)\right\}\right] \\
\alpha_{c}=-0.5 \quad \alpha_{a}=0.5
\end{gathered}
$$

where

$$
\begin{aligned}
& E_{e q}=\text { equilibrium potential from the Nernst Equation } \\
& E=\text { corrosion potential versus } \mathrm{SHE}=\phi_{M}-\phi_{S} \\
& \alpha=\text { transfer coefficient } \\
& i=\text { current density }\left(\mathrm{A} / \mathrm{dm}^{2}\right) \\
& a, c=\text { anodic, cathodic. }
\end{aligned}
$$

Anodic reaction kinetics are assumed to be active subsequent to the beginning of attack.

$\mathrm{Fe}(\mathrm{s}) \Leftrightarrow \mathrm{Fe}^{2+}+2 \mathrm{e}^{+}$

For active metal surfaces the anodic kinetics are described by the Butler-Volmer equation

$E_{e q}=-0.44+\frac{R T}{2 F} \log \left(F e^{2+}\right)$

$k=1.99 \times 10^{5} \exp \left\{\frac{\alpha_{n} F E_{e q}}{R T}\right\}$

$i_{F_{e}}=k\left[-\exp \left\{\frac{\alpha_{c} F}{R T}\left(E-E_{e q}\right)\right\}+\exp \left\{\frac{\alpha_{a} F}{R T}\left(E \ldots E_{e q}\right)\right\}\right]$

$\alpha_{c}=-1.0 \quad \alpha_{a}=1.0$.

Mass Transport. The equation for transport of dissolved electrolytes in dilute solutions, subject to advection diffusion and electromigration, is (Newman, 1973)

$\vec{J}_{i}=-n D_{i} \vec{\nabla} C_{i}-\frac{n z_{i} D_{i} F}{R T} C_{i} \vec{\nabla} \phi+V C$ 
where

$$
\begin{aligned}
& \left.\vec{J}=\text { transport flux (moles } / \mathrm{dm}^{2} \mathrm{~s}\right) \\
& n=\text { liquid porosity } \\
& D=\text { diffusivity }\left(\mathrm{dm}^{2} / \mathrm{s}\right) \\
& \left.C=\text { concentration (moles } / \mathrm{dm}^{3}\right) \\
& z=\text { charge number } \\
& \phi=\text { electrostatic potential in solution (volt) } \\
& \vec{\nabla}=\text { vector gradient operator } \\
& V=\text { Darcy Velocity }(\mathrm{dm} / \mathrm{s}) .
\end{aligned}
$$

For uncharged species and/or when advection dom inates the electromigration term becomes unimportant. Solution of the mass transport and chemical reaction equations (Walton and Sagar, 1987, 1988 and Harker et al., 1987) suggests that oxygen levels quickly become depleted followed by buildup of hydrogen gas in the system. Corrosion rates then become limited by the diffusion rate of oxygen gas in the system and the kinetics of the hydrogen evolution reaction.

\section{Example Calculations}

The predictions of the simple models are illustrated in the following figures. Figures 12 through 15 give time to initiation of corrosion from Equation (1) as a function of WCR, chloride concentration, and depth of concrete cover over the reinforcement. The empirical cquation contains no provision for a threshold chloride concentration and may be overly conservative. All of the graphs apply the empirical equation well outside the bounds of the data the equations were derived from with obvious implications for the quality of the predictions.

Figure 15 illustrates the calculated corrosion rate subsequent to initiation of corrosion assuming limitation by oxygen diffusion from Equation (7). Oxygen diffusion rates in aclual systems become enhanced over time as processes such as calcium hydroxide leaching and sulfate attack lower the effective reinforcement cover thickness and increase mass transport rates. No altempt has been made to illustrate the coupled effects from multiple types of concrete attack. in the example calculations.

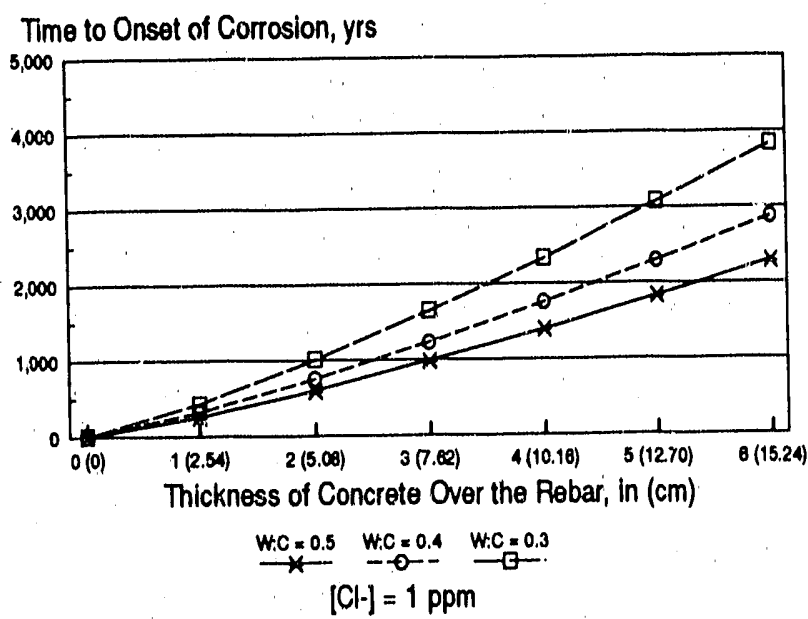

Figure 12. Time to initiation of reinforcement corrosion by empirical model as a function of WCR and depth of cover with soil chloride concentration of $1 \mathrm{ppm}$.

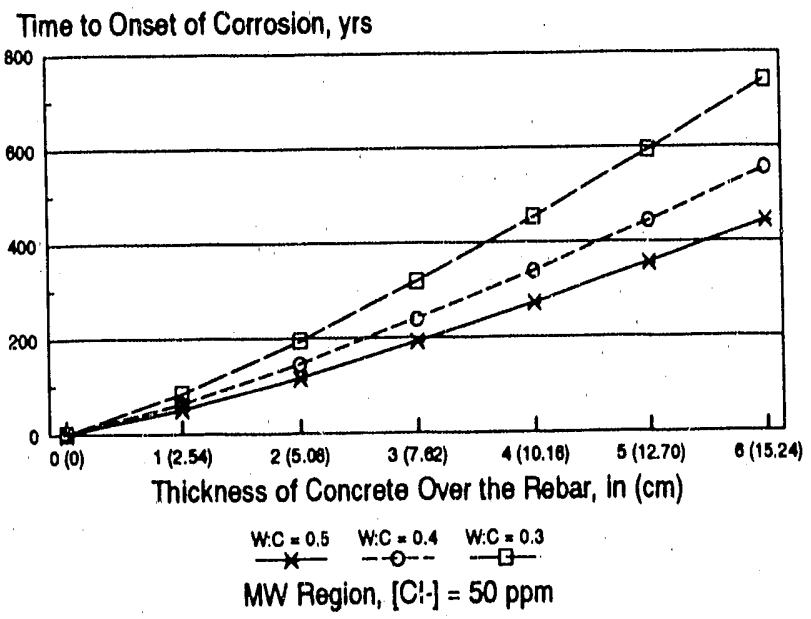

Figure 13. Time to initiation of reinforcement corrosion by cmpirical model with $50 \mathrm{ppm}$ chloride in soil moisture.

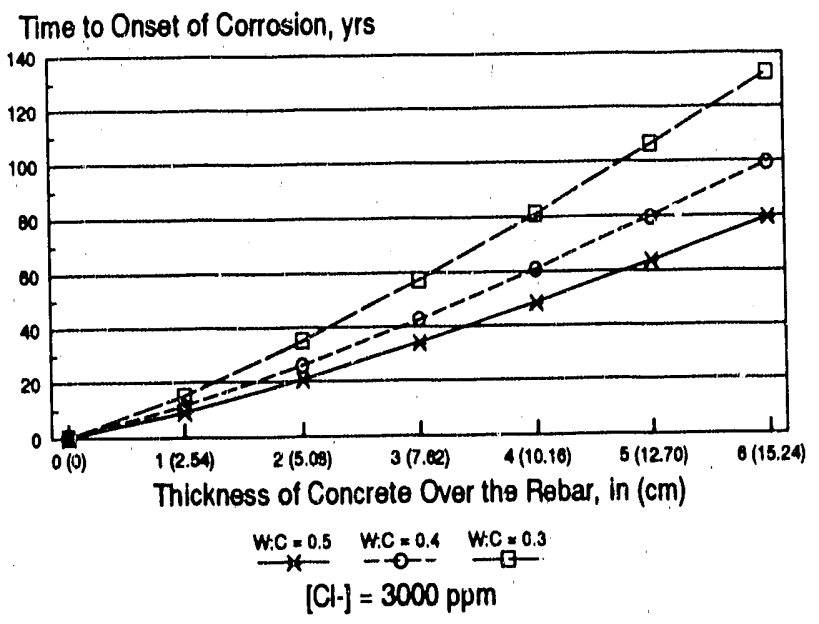

Figure 14. Time to initiation of reinforcement corrosion bv empirical model with $3000 \mathrm{ppm}$ chloride in soil moisture. 


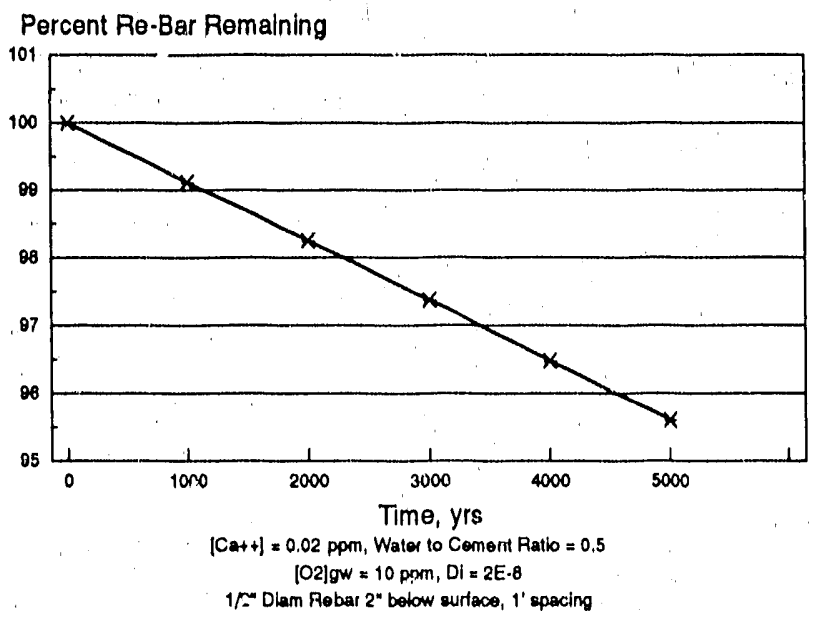

Figure 15. Example of oxygen limited corrosion rate subsequent to initiation of corrosion. 


\section{LEACHING}

Cement components will be leached from concrete in environments that are in contact with water and have significant water percolation rates. The alkalis are initially affected followed by calcium hydroxide. The alkalinity of the concrete pore water decreases as the leaching process progresses.

Based upon modeling and experimental results, Atkinson (1985) and Atkinson et al. (1988) describe four stages of leaching. The time frames involved with each stage are dependent primarily upon water flow rates through the concrete. The four stages are

1. Initially, the pH is around 13 due to the presence of alkali metal oxides and hydroxides. The alkali metals are the first components to leach from the concrete.

2. After the alkali metals are leached, the $\mathrm{pH}$ is controlled at 12.5 by solid $\mathrm{Ca}(\mathrm{OH})_{2}$.

3. Following loss of calcium hydroxide, the calcium silicate hydrate (CSH) gel phases begin to dissolve incongruently while the $\mathrm{pH}$ slowly moves down to 10.5 . During this period, the calcium to silicon ratio drops to 0.85 .

4. In the final phase, the pII is held at 10.5 by congruent dissolution of the CSH gel.

Leaching of calcium hydroxide tends to lower the strength of cement. The strength is lowered approximately $1.5 \%$ for evcry $1 \%$ of calcium lost (Lea, 1970). In advective environments, at least $66 \mathrm{~m}^{3}$ of water is required to remove $33 \%$ of the calcium from $1 \mathrm{~m}^{3}$ of typical concrete (Atkinson and Hearne, 1984).

\section{Models of Leaching}

Concrete Controlled Leaching. A shrinking core model has been applied by Atkinson and Hearne (1984) to evaluate leaching. The shrinking core model can be given by

$\mathrm{Ca}(\mathrm{OH})_{2} \Rightarrow \mathrm{Ca}^{2+}+2 \mathrm{OH}^{-}$

$F l u x=-D_{i} \frac{C_{l}-C_{g w}}{X}$

$\frac{d X}{d t}=\frac{D_{i}}{X} \frac{C_{1}-C_{g w}}{C_{s}}$

$\ddot{X}=\left(2 D_{i} \frac{C_{l}-C_{g w}}{C_{s}} i\right)^{\frac{1}{2}}$ where

$$
\begin{aligned}
C_{l}= & \text { concentration of } \mathrm{Ca}^{2+} \text { in concrete pore waters } \\
& \text { liquid (moles } \left./ \mathrm{cm}^{3}\right) \\
C_{s}= & \text { bulk concentration of } \mathrm{Ca}^{2+} \text { in concrete solid } \\
& \text { (moles } \left./ \mathrm{cm}^{3}\right) \\
D_{i}= & \text { intrinsic diffusion coefficient of } \mathrm{Ca}^{2+} \text { in } \\
& \text { concrete }\left(\mathrm{cm}^{2} / \mathrm{s}\right) \\
C_{8 w}= & \text { concentration of } \mathrm{Ca}^{2+} \text { in groundwater or solu } \\
& \text { moisture }\left(\text { moles } / \mathrm{cm}^{3}\right) \\
\mathbf{x}= & \text { distance }(\mathrm{cm}) \\
\mathrm{N}= & \text { molar flux }\left[\text { moles } /\left(\mathrm{cm}^{2} \mathrm{~s}\right)\right] \\
\mathrm{t}= & \text { time }(\mathrm{s}) .
\end{aligned}
$$

The shrinking core model assumes that removal of calcium from the exterior of the concrete is rapid relative to the movement through the concrete. Thus, the transport rate is controlled by diffusion in the concrete. Note that the formulation only includes diffusional mass transport. A more sophisticated model could include the influence of advection through and around the concrete. Because concrete is much less permeable than surrounding geologic materials, the dominant flow direction will rarely be normal to the concrete surface. Rather water tends to flow laterally around the concrete mass. This type of problem could be analyzed with two or three dimensional numerical flow and transport codes.

The intrinsic diffusion coefficient in the calculations applies to the leached or depleted portion of the concrete. Thus, it can be expected to bu substantially higher than the $D_{i}$ for intact concrete. The permeability of the concrete will also increase as leaching procedes, which leads to enhanced flow rates in the leached region (i.e., diffusion may no longer dominate transport).

Geology Controlled Leaching. An alternative formulation (Figure 16), also by Atkinson and Hearne (1984), assumes that diffusion into the surrounding geology is controlling. When diffusion is from a fixed concentration into a semi-infinite domain, then concentrations are described by an error function (Crank, 1975)

$\frac{C-C_{g^{w}}}{C_{l}-C_{\delta^{w}}}=\operatorname{ercf}\left(\frac{X}{\left(\frac{D_{E^{l}}}{R_{d}}\right)^{\frac{1}{2}}}\right)$.

The instantaneous flux at $X=0$ is obtained by differentiation of the concentration profile 
The total amount of material leached (per unit area) during a given time period is obtained by integrating with respect to time

$M_{1}=\phi C_{l}-C_{g \omega}\left(\frac{4 R_{d} D_{E} t}{\pi}\right)^{\frac{1}{2}}$.

The total amount of calcium hydroxide removed (per unit area) can be related to the inventory in the concrete as

$M_{1}=X C_{b}$

$X=2 \phi \frac{C_{l}-C_{g w}}{C_{b}}\left(\frac{R_{d} D_{E} t}{\pi}\right)^{\frac{1}{2}}$

where

$$
\begin{aligned}
C_{l}= & \text { concentration of calcium in the concrete pore } \\
& \text { water } \\
C_{b}= & \text { concentration of calcium in the bulk concrete } \\
& \text { (solid + pores). }
\end{aligned}
$$

The assumption of surrounding geology limiting calcium hydroxide depletion is used in the Barrier Code (Shuman et al., 1989). Note that the transport parameters $\left(R_{d}, D_{E}, p\right)$ in the geology controlled leaching model pertain to the surrounding geologic medium, not the concrete.

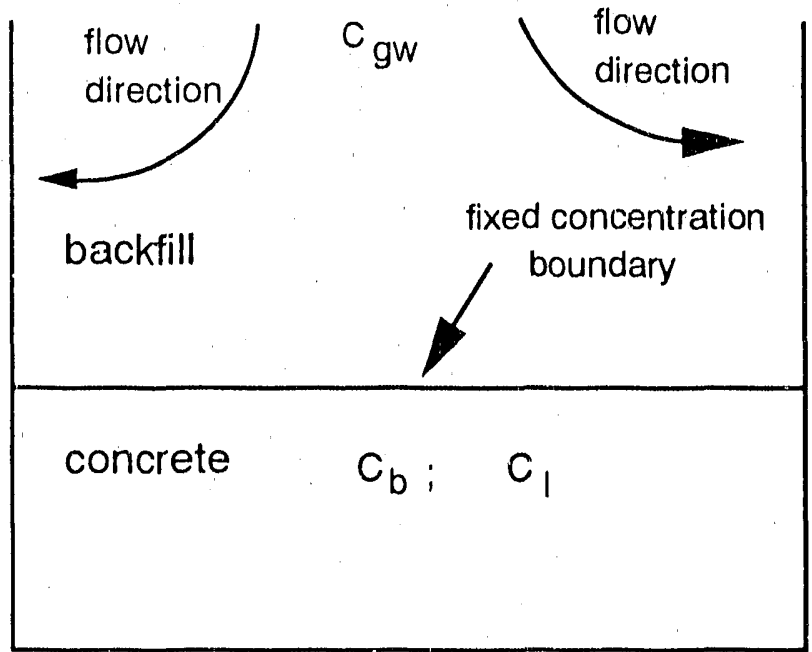

\section{Vault Interior}

Figure 16. Schematic of calcium hydroxide leaching.

The impact of calcium hydroxide leaching has been estimated by assuming that the concrete loses half its strength when $33 \%$ of the calcium hydroxide has been depleted (Lea, 1970). Atkinson and Hearne (1984) simply assume the concrete fails when one third of the calcium in the layer is depleted. In the Barrier code (Shuman et al., 1989), an exponential loss of strength is (apparently) assumed
$Y=Y_{o}\left[1-\left\{\left(\frac{X}{X_{t}}\right)\right\}^{\alpha}\right]$

Where $Y$ is the yield strength of the concrete, $Y_{0}$ is the initial yield strength, and $X_{1}$ is the concrete thickness. Assuming that half the yield is lost at $33 \%$ depletion gives a value of 0.625 for $\alpha$. The Barrier code documentation omits the normalization of $\mathrm{X}$ by $\mathrm{X}_{1}$ in the governing equation.

Alcorn et al. (1989) derive an expression for the change in hydraulic conductivity as a function of the change in porosity using data from different sources. The result is

$\Delta K=K_{0}^{*} 10^{\left(11.14^{*} \wedge \phi^{4}\right)}-K_{0}$

where

$$
\begin{aligned}
\Delta K= & \text { the change in hydraulic conductivity of the } \\
& \text { concrete } \\
K_{0}= & \text { initial hydraulic conductivity of the concrete } \\
\Delta \phi= & \text { change in porosity of the concrete. }
\end{aligned}
$$

The relationship is based on regressions of experimental data from various sources. The estimates from the equation are expected to be highly uncertain.

An analysis of combined geology and concrete cuntrolled leaching along with fluid flow could be analyzed with numerical flow and transport codes if a more sophisticated approach was warranted.

\section{Example Calculations}

The predom inant flow system for a concrete vault located in the vadose zone systern is one of water moving around the concrete vault. This water could serve to remove calcium from the surface. The leaching process can be estimated using the shrinking core model (Atkinson and Hearne, 1984) for concrete controlled leaching. Figure 17 illustrates the predictions of the shrinking core model of leaching. Leaching is most rapid in locations with lower calcium concentrations.

Figure 18 illustrates the predictions for geology controlled leaching using the parameter assumptions listed on the figure.

Both sophisticated and simplistic models of leaching suggest that significant amounts of leaching require time frames in the thousands of years - quite long in the context of low-level radioactive waste disposal. 


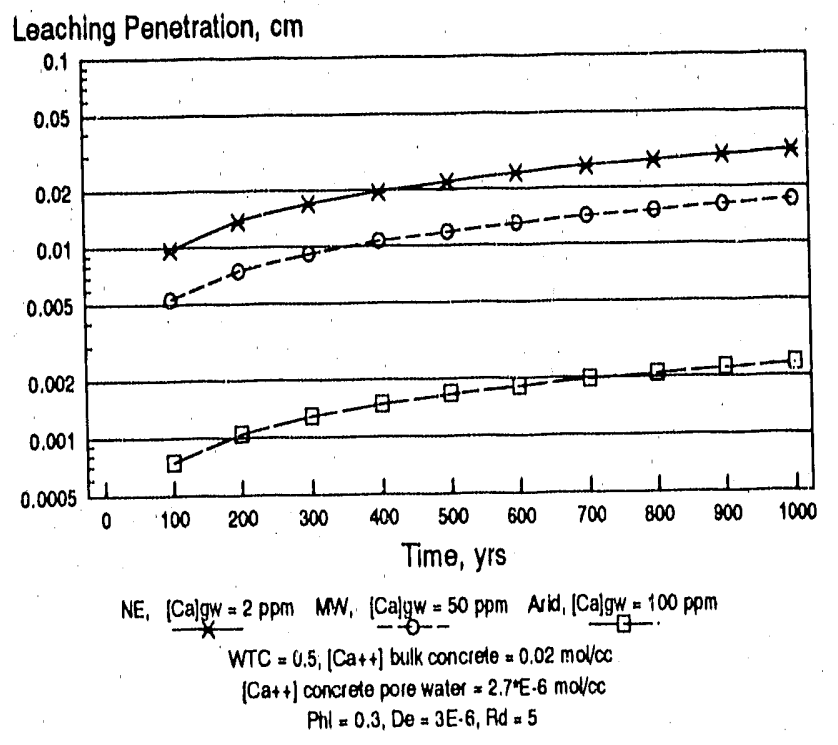

Figure 17. Calcium hydroxide leaching assuming concrete control in northeast, midwest, and arid environments.

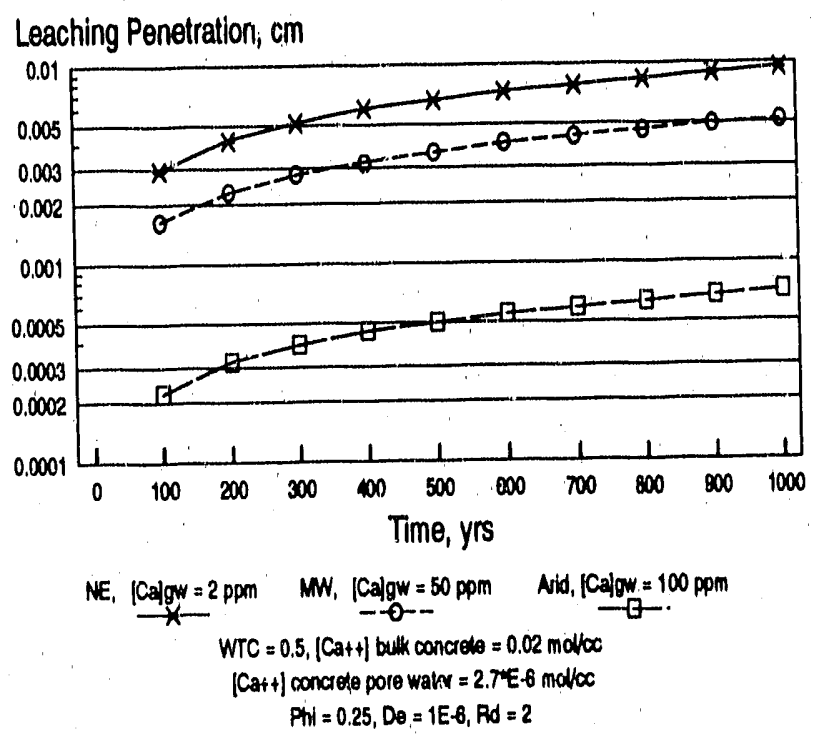

Figure 18. Calcium hydroxide leaching assuming geology control. 


\section{CARBONATION}

\section{Carbonation}

Carbon dioxide reacts with cement components to form carbonates - a process referred to as carbonation. The reaction is represented by

$\mathrm{Ca}(\mathrm{OH})_{2}+\mathrm{H}_{2} \mathrm{O}+\mathrm{CO}_{2} \Rightarrow \mathrm{CaCO}_{3}+2 \mathrm{H}_{2} \mathrm{O}$.

The depth of carbonation is roughly proportional to the square-root of time, doubling between 1 and 4 years, then doubling again between 4 and 10 years (Neville, 1981). The rate of carbonation depends upon the moisture content of the concrete and the relative humidity of the ambient medium. If diffusion in the concrete is too slow, an equilibrium is reached where the diffusion of $\mathrm{CO}_{2}$ and cartionation are stopped or severely reduced. The type of cement ultim: tely affects the depth of carbonization.

Untike other degradation processes, carbonation is not inconsistent with long-term durability of concrete. Carbonation does not cause general disruption or increased permeability of the concrete matrix. The formation of calcium cartonate may even slow migration of some radionuclides through solid solution reactions. Many concreles surviving from Roman times are fully carbonated. Carbonalion is associated with two potentially negative changes in concrele material properties, shrinkage, and a drop in pll.

The total shrinkage from carbonation can be in the range of 0 to $0.1 \%$ (Verbeck, 1958). The shrinkage is thought to occur (Powers, 1962) as the minerals are removed from areas of coripressive stress and redeposited in regions of lower stress. The compressive stress can occur as a result of capillary forces in a partially dried concrete. This can explain why carbonation under saturated conditions does not result in shrinkage since capillary forces are absent at saturation. The strength of concrete generally increases under carbonation, with the exception of high sulfate concretes. Carbonation of hydrated Portland-cement pastes also results in reduced permeability and increased hardness (Verbeck, 1958). The excess shrinkage may result in increased cracking and/or joint permeability. Carbonation forces the local pll toward neutral, going from over 12 to about 8 , thereby removing some chemical barrier benefits of the concrute and providing a potentially corrosive environment for sted reinforcements if water, moisture, and oxygen can penetrate.

The rate of carbonation is dependent upon water saturation or relative humidity of the environment. As relative humidity increases from 0 to $100 \%$, the rate of carbonation passes through a maximum. The maximum rate of carbonation occurs because water is required in the reaction of $\mathrm{CO}_{2}$ and $\mathrm{Ca}(\mathrm{OH})_{2}$ to form $\mathrm{CaCO}_{3}$, but increasing water contents slow the diffusion rate of $\mathrm{CO}_{2}$ through the concrete.

\section{Sources of Carbon Dioxide}

Carbon dioxide, in the presence of moisture, reacts with hydrated cement minerals in the form of carbonic acid. Carbon dioxide occurs as a minor constituent of air and a major component of carbonate rocks. Carbon dioxide is also generated from decomposition of organic materials in soils and/or waste.

\section{Models of Carbonation Attack}

Based upon Equation (1), a shrinking core model can be derived for carbonation. Carbonation can occur only as rapidly as dissolved carbonate can diffuse through the concrete. At the high pH relevant to concrete, Equation (1) actually occurs as

$\mathrm{Ca}(\mathrm{OH})_{2}+\mathrm{CO}_{3}^{2-} \Rightarrow \mathrm{CaCO}_{3}+2 \mathrm{OH}^{-}$.

However, the transport of carbonate through the concrete can occur either as carbonate in the aqueous phase or carbon dioxide in the vapor phase. Since vapor phase diffusion is approximately four orders of magnitude more rapid than aquecous diffusion, one would expect rates of carbonation to increase as the saturation level of the concrete decreases at least until the water required for the reaction becomes in short supply. Verbeck (1958) found that carbonation rates peak at $50 \%$ relative humidity, consistent with this observation.

A shrinking core model for carbonation can be formulated by evaluating the migration rate of $\mathrm{CO}_{2}$ into the concrete in relation to the initial amount of calcium hydroxide. Although carbonation is most rapid at 50\% relative humidity when significant amounts of water have been removed from the concrete, typical subsurface environments approach $100 \%$ relative humidity. Under these conditions, the concrete matrix remains water saturated because of the small pore sizes relative to surrounding soil materials. In most concrete vaults in the vadose zone, the transport of $\mathrm{CO}_{2}$ is in the liquid phase, resulting in slow rates of carbonation. The following shrinking core derivation is valid for water saturated concrete: 
$F \operatorname{lux}=-D_{i} \frac{C_{g^{w}}}{X}$

$\frac{d X}{d t}=\frac{D_{t} C_{g w}}{X} \frac{C_{s}}{C_{s}}$

$X=\left(2 D_{i} \frac{C_{g w}}{C_{s}} t\right)^{\frac{1}{2}}$

where

$C_{s}=$ bulk concentration of $\mathrm{Ca}(\mathrm{OH})_{2}$ in concrete solid $\left(\mathrm{moles} / \mathrm{cm}^{3}\right)$

$D_{i}=$ intrinsic diffusion coefficient of $\mathrm{Ca}^{2+}$ in concrete $\left(\mathrm{cm}^{2} / \mathrm{s}\right)$

$C_{8 w}=$ concentration of total inorganic carbon in groundwater or soil moisture $\left(\mathrm{molcs} / \mathrm{cm}^{3}\right)$

$\mathrm{x}=$ distance $(\mathrm{cm})$

$\mathrm{N}=\operatorname{molar}$ flux $\left[\operatorname{molcs} /\left(\mathrm{cm}^{2} \mathrm{~s}\right)\right]$

$\mathrm{t}=\operatorname{time}(\mathrm{s})$.

Papadakis et al. (1989) have developed a rigorous mechanistic model for carbonation of concrete. The model considers mass transport, chemical reaction, and reaction kinetics. The model predicts that carbonation rates will peak as relative humidity is decreased from 100 to $50 \%$. Below $50 \%$, relative hum idity reaction rates decline rapidly leading to slower rates of carbonation. In the range of 50 to $100 \%$ relative humidity, the model can be simplified to a shrinking core model similar to that given above. The derivation assumes partially saturated conditions (i.e., vapor phase diffusion of $\mathrm{CO}_{2}$ dominates), thus the diffusion coefficient and concentration of $\mathrm{CO}_{2}$ reflect vapor phase values.
Experimental values of the diffusion coefficient as a function of relative humidity are included in the paper (Papadakis et al., 1989).

Concrete degradation by carbonation is not (currently) considered in the Barrier code.

\section{Example Calculations}

The rate of carbonation by the shrinking core model is shown in Figure 19. The predicted rate of carbonation is slow for subsurface vaults because they are assumed to remain at full water saturation. Vaults that are located above the land surface or in highly desicated (i.e., desert) environments where relative humidity is significantly below $100 \%$ will experience more rapid rates of carbonation.

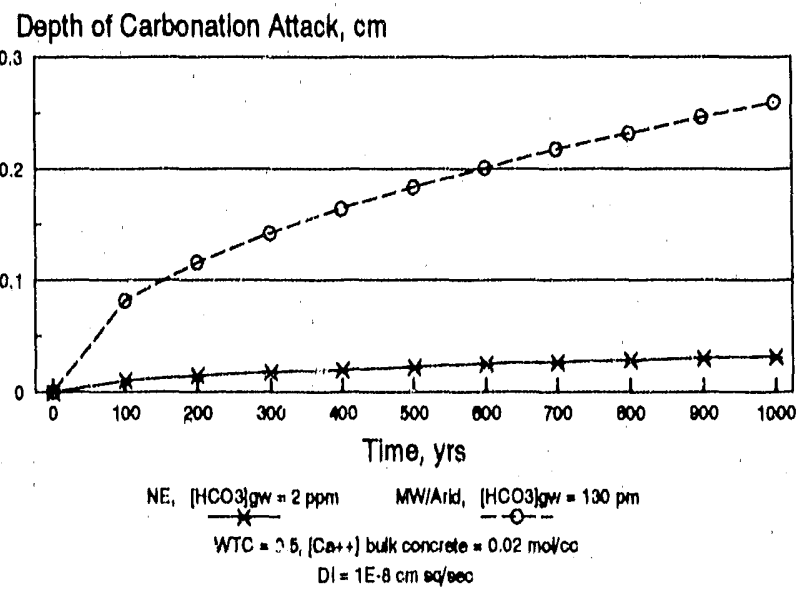

Figure 19. Rate of carbonation by shrinking core model in different geochemical environments. 


\section{ALKALI AGGREGATE REACTION}

Aggregate is an additive to OPC that consists of particles of natural or artificial rock materlal of varying shapes ranging in size from tens of millimeters down to tenths of millimeters in cross section. Three quarters of the volume of concrete may be occupied by aggregate. Chemical reactions with the aggregate cause irreversible changes in concrete and play an important role in the physical, thermal, and chemical properties as well as in concrete durability and performance (Neville, 1981).

Three categories of deleterious substances may be found in aggregate (Neville, 1981): Impurities that interfere with the cement hydration process, coatings that prevent the development of a good bond between the aggregate and the OPC paste, and weak or unsound aggregate particles.

A variety of processes may take place because of reactions between the components of the $\mathrm{OPC}$ and individual components or impurities of the aggregate, in particular, the reactions involving the alkali components of the cement paste (alkaline hydroxides derived from alkaline oxides in the cement) and the presence of active siliccous components in the aggregate (e.g., opal, chalcedony, or tridymite). An alkaline silica gel forms that alters the borders of the aggregate and leads to abnormal expansion, cracking, and loss of strength. This process is known as alkall aggregate reaction. Other degrading reactions of the aggregate iriclude the oxidation of mineral oxides and sulfides or an alkali carbonate reaction - the reaction of carbonate in the aggregate with the alkall of the cement.

Alkall aggregate reaction can be reduced by the careful selection of aggregate and the elimination of the alkali components in the cement paste. It has also been found that the introduction of finely powdered reactive silica to the cement mix reduces or eliminates the reaction. This is due to the increased area of the reactive sillca with less alkall per unit area being avallable (Neville, 1981). The alkali aggregate reaction is highly complex, and no mathematical models have been found to estimate its progression. 


\section{FREEZE/THAW}

Concrele struclures that are not burled below the locell freezing depth will be subject to freeze/thaw cycles. Even structures built (or mounded) to depths below the freezing level will be subject to freeze/thaw processes during the operational phase of the fiedlity. Upon freceing, water in the capillary pores of the concrete freezes and expands in volume by approxirnately $9 \%$. Depending upon a varicty of factors including number of frecec/thaw cycles, rate of freczing, concrete permeability, walter salturation, water avallabilily, aggregate, salt content, and amount of entrained air, degradation of the concrete can occur. Failure of the concreie generally takes the form of loss of strength and/or crumbling (Detwiler et al., 1989).

Two processes are considered to caluse frecze/thaw damage (1) hydraulic pressure and (2) tec accretion (Detwiler et al., 1989; Clifton, 1990). Hydraulic pressure occurs whon waler in large pores cxpands upon freczing, The excess pressure can only be relleved when the excess waller migrates to vold spaces, such as the volds calused by air enirainment. Klieger (1980) suggests that (xsmotic forces may also be important during freezing. Salls in the solution are excluded from the ice crystals, leading to greater concentrations in the water moving away from the ice. The higher sall concentrallions lead to counter osmotic forces that further increase the excess pressure. This proposed mechanism explains the negative impact that deicing chemicals have on freeze/thaw durability. The osmotic mechanism is a physlaal process consistent with experiments illustralling that widely different chemical compounds can have similar influences on frecze/thaw damage (Klieger, 1980), The hydraulic pressure mechanism is most important during rapid frecze/thaw cycles.

Ice accretion occurs when freczing ealuses a lowering of vapor pressure in the large pores. Water in the gel pores remains in a liquid state because of capillary attraction in the very small pores. Gel waler freezes at a temperature below $-78^{\circ} \mathrm{C}$ (i.c., gel waller does not freeze in any expected service environments). The supercooled gel water then migrales to the large pores calusing expansive forces around the large pores and compressive forces in the gel pores. The ice accretion mechanism is most important during extended periods of freczing (Detwilcr et al., 1989).

Detwiler et al. (1989) list air entrainment, WCR, aggregate composition, and curing as the factors most important for making concrete that is resistant to freeze/thaw. Air entrainment works by providing ope.. pores for relief of excess pressure. When air voids are properly spaced the local pressure will never exceed the tensile strength of the concrele resulting in a very resistant concrete.
Total frecze/thaw deimage depends both upon the resistance of the concrete to freeze/thaw and the agresstec properties of the service environment. Propertles of the service environment that lead to damage are high water saturation of the concrele, large number of freeze/thaw cycles, and high salt content (Klieger, 1980). Typlcally a concrete has a critical water saluration level above which the material becomes very susceptible to damage.

Two testing methods for frecze/thaw resistance have been commonly used. These are contained in American Socicly for Testing and Matcrials (AS'IM) Standard C 666-77. Both methods use rapid freczing first, but in one both freezing and thawing take place in water, while in the other freezing takes place in air and thawing in water. The former method is more severe than the latter (Neville, 1981). With these ASTM methods, freczing and thawing is done for 300 cycles or until the dynamic modulus of elasticily is reduced to $60 \%$ of its original value. A durability is computed from

durability factor $=[$ (final_number_test_cycles)

(\%_of_original_modulus) $) / 300$.

There are no established criteria for the acceplance or rejection of concrete in terms of this durability factor. Its value is primarily for comparison of concretes. Usually, however, a factor sinaller than 40 mains the concrete is probably unsalfactory with respect to frecze/thaw resistance or damage; 401060 is the range for concrete with doubtful performance; and, above 60, the concrete is probably satisfactory (Neville, 1981).

\section{Models of Freeze/Thaw Performance}

Several models of frecze/thaw durability have been proposed. A review of several of the frecze/thaw models, as well as an introduction to the problem is given by Clifton (1990). The models range in complexily from empirical to a full solution of the fluid flow, temperature, and stress equations as proposed by Bazant et al. (1988). The discussion below cuvers the model used in the Barrier code (Shuman et al., 1989).

In the Barrier code, freeze/thaw durability is modeled by a fit of data that expresses the fractional decrease in dynamic modulus of elasticity (DME) of the concrete as a curve fit involving the \% entralned air (AIR), waler-to-cement rallo (WCR), and the number of freeze/thaw cycles. The viriation of DME is taken to be linear when the number of freeze/thaw cycles is greater than 50; this is based on experimentai results. The expression fit used in the Barrier code is 


$$
Y 1=\frac{(\text { NumCycles }-50)}{\left(\left(275^{*} A I R\right)^{*}\left(1.0+0.43^{*} A / R\right)^{*} F(W C R)-100,0\right)}
$$

whore

$F(W C R)=4.2-8.0 * W C R *(1.0-0.4 * W C R)$

$\mathrm{Y} 1=$ the fractlonal decrease in dynamic modulus of clestideity of the concrete

$\mathrm{N}^{\prime}=$ nurnber of frecze/thaw cycles

AIR $=$ percent cntralned air in the concrele

WCR $=$ water-to-cement rullo.

$Y 1=0.5$ is taken as the point of signifleant cracking and deterioralion of the concrete due to freeze/thew action. 'The amount of time ( $\mathrm{Tc}$ ) required to reach this level of damage is given by

$T_{c}=\left(138^{*} A I R\right) / N^{*}\left(1.0+0.43^{*} A I R\right)^{*} I^{\prime}(W C R)$,

The annual rate of degradation $\left(R_{r}\right)$ is given by

$R_{f l}=\left(N / T_{c}^{\prime}\right) *\left(\frac{0.05}{\sqrt{(\theta)}}-0.21 * T_{r}\right)$

where

$$
\begin{aligned}
& \theta=\text { walter content } \\
& \mathrm{T}_{1}=\text { residual walter content (assumed }=0.09 \text { ). }
\end{aligned}
$$

The Barrier code also computes the amount of time required to reach a given level of damage for a given value of fractional decrease in DME ats well ats an annual rate of concrete losss. The bartier data are, in part, based on the work of Pigcon et al. (1989).

An example of froeze/thaw loss predloted by the Barrier code equations is glven in Figure 20.

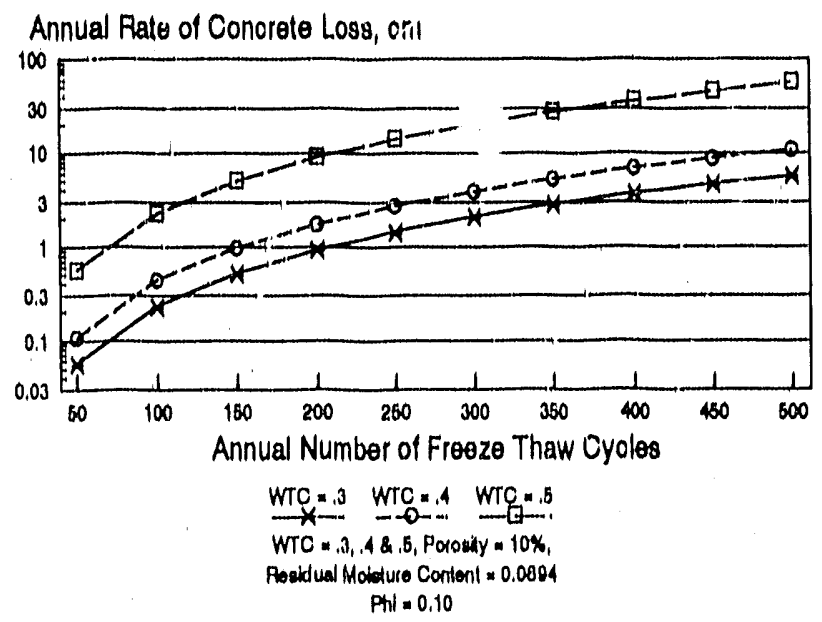

Figure 20. Loss from freeze/thaw damage with 7\% entrained air. 


\section{CRACKING}

Cracking call result from a number of phenomena including, dryling shrinkage, lemperature change stress, reinforcement corrosion wilh resulling expansion, carbonation, and physlaal loadings, the location and nalure of a criok depends upon the caluse. Current understanding of concrete cracking was summarlacd by an $\mathrm{ACI}$ comm ittees (ACI, 1984, 1990).

The simplest form of crack is caused by physical londing on the roof of the structure. This leads lo a set of partially penctralling cracks below the neutral ax is of the slab (Figure 21). A lot of work has been done in predicting the locatlon and size of cracks formed by physleal loading of concrete beams and slabs (Broms, 1965; Bazant and Oh, 1983; Oh and Kang, 1987). A variely ol lormulac has been developed for crack prediction, In euch casc, the most important parameler is the amount of strain in the steel reinforcement.

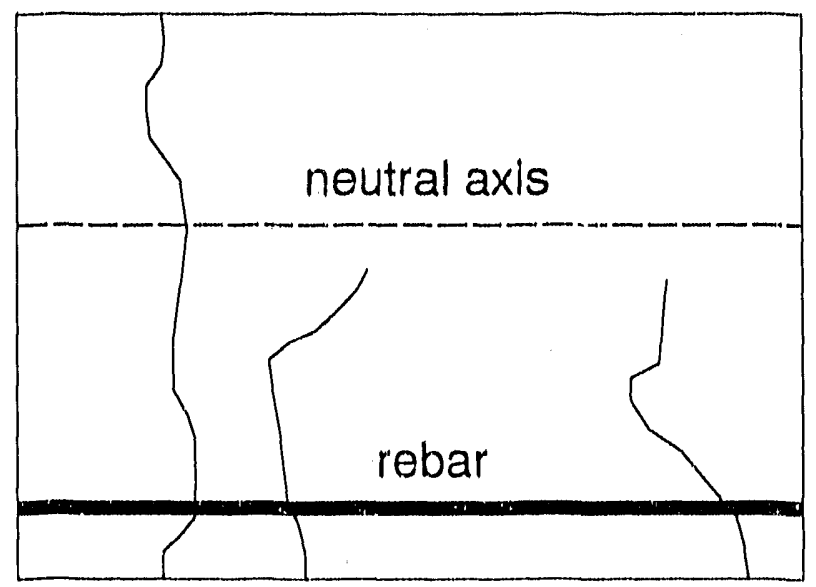

Nigure 21. Schemaltic of cracks.

Microcracks in concrete may also be calused by drying shrinkage. As the concrete dries, the capillary pressure generated leads to shrinkage. Drying shrinkage leads to systenis of parallel cracks that are usually too thin to be visible by the unaided eye (Bazant and Raftshol, 1982). This type of drying might occur during the operational perlod of a belowground vaull. Lven very tiny microcracks lend to dominale the permeability of the concrele at low pore water tenstons.

Phenomena that cause general shrinkage of concrete, such as drying and carbonation, can lead to crack formation. Either drying shrinkage or carbonation cun lead to shrinkange In the range of $0.08 \%$, depending upon the moisture content at exposure. Combined, they can lead to $0.16 \%$ strinkage. Lower molsture contents lead to greater drying shrinkage, whereas shrinkage from carbonation peaks at a relative humidity of 50\% (Verbeck, 1958), T'omprarature changes leading to swelling and shrinkage of the concrete also caluse cracking.

\section{Penetration Assumptions}

One of the most crucial aspects of the evaluation of cracking is the assumption concerning penctration of the cracks. Me t cracks from flexural loading are expected to penctrate only from the bottom of the roof to the neutral axis. Above the neutral axis, in the zotie of compresslve stress, most cracks would not be expected to penetratc. In the Barrier code (Shuman et al., 1989), cracks from phystcal loading are atssumed inittally to penatrate only to the reustral axis and not affect the hydrologic properties of the slab. Once the cracks reach a depth of three-fourthes of the slab thickness or wilthin $7.5 \mathrm{~cm}$ of the tolal slab thickness, they are assumed to fully penetrate the slab. The increased hydraulic conductivily cealused by the crack is then added to the slab permeabillty in the form of an equivalent porous media. 'The specifics of the calculation of crack width, spacing, and unsaturated hydrologic properties in the Barrier code are not well documerted.

Cracks resulling from volume changes in the concrete calused by temperature changes, drying shrinkage, and carbonation are more likely to penetrate the entire slab thickness, Penctration of the slab is factlitated by the absence of compressive forces at the top of the concrete slab.

\section{Crack Prediction - Flexural Beams}

The prediction of crack width and spacing in concrete flexural members has been the subject of a falr amount of research. The simplest expressions can be attributed to Broms (1965). Average crack spacing was given as

$S_{\text {avg }}=2 t$.

Average and maximum crack widths were given as

$$
\begin{aligned}
& W_{\text {avg }}=2 t e_{t} \\
& W_{\max }=1.66 W_{\text {avg }}
\end{aligned}
$$

where

$$
\begin{aligned}
& \mathrm{t}=\text { concrete thickness over sted } \\
& \mathrm{e}_{3}=\text { strain in the steel reinforcement } \\
& \mathrm{S}=\text { crack spacing } \\
& \mathrm{W}=\text { crack width at tension face. }
\end{aligned}
$$

Broms (1965) and Broms and L.utz (1965) made several observations concerning the nature of the cracks: 
1. Primary tensile cracks could be observed on the surface of flexural members. The cracks extended to the noutral axis. Secondary tensile cracks were obsereded when the stress in the reinforconent reached approximately 20,000 - 30,000 pxil. Thase cracks were confined to the immediate vicinily of the reinforcement. Longltudinal tensile cracks, which started at existing primary or secondary cracks and spread along the reinforcement, were noticed at the highor strain. Longltudinal cracks, which formed in the compressiton zone, were observed for the flexural mombers at high load levels.

2. "The surface crack width will be small if the reinforcement is distributed undformly along the pertiphery of a momber, If a large number of small dameter bars are used and if these bars are placed as close to the surface as ferasible."

Bazent and Oh (1983) derived theoret leal exprassions for crack spacing in relnforced concrele. 'Ihess: expresssions Indicaled good numerical nercement with the empirical Gergely-Lulz formula, Later Oh and Kang (1987) developed simpler, easier to use expressions for maximium crack widt hand crack spacing in concrete flexural mombers. 'Ihese equations glve a beller fit to the data than the Gergely and Lutz formula.

The equalions for maximum crack width are

$\frac{W_{\max }}{D}=a_{11}\left(\varepsilon_{s}-0,0001\right) R$

$a_{0}=1.59\left(\frac{t_{6}}{h_{2}}\right)^{4.5}+2.83\left(\frac{A_{1}}{A_{s 1}}\right)^{1 / 3}$

$R=\frac{h_{2}}{h_{1}}$

whore

$w_{\max }=$ maximum crack width at extreme tension face

$h_{2}=$ distance between neutral axis and lower face

$h_{3}=$ distance between neutral axis and sted reinforcement center

$A_{1}=$ efflective area of concrete surrounding one reinforcement bar

$A_{s l}=$ area of one reinforcement bar

$t_{b}=$ boltom concrete cover over reinforcement

$D=$ reinforcement bar diameter

$\varepsilon_{s}=$ stcel strain.

To predict crack spacing, the following equation was used
$\frac{s}{D}=c_{0}+\frac{0.236 \times 10^{-6}}{\varepsilon_{s}^{2}}$

$c_{0}=25.7\left(\frac{t_{b}}{h_{2}}\right)^{1.5}+1.66\left(\frac{A_{1}}{A_{s l}}\right)^{\frac{1}{j}}$

where $s$ is the a verage spacing of cracks. The average crack width at the surface using this formula would be

$w_{\text {avy }}=s \varepsilon_{s} R$.

These equations are espectally conventent because of the dimensionless format.

\section{Crack Predictlon - Volume Change}

Prediction of cracks caused by concrete volume changes is covered in ACI 207 (ACI, 1990), Volume change generally comes from temperature itse during selting, scasonal temperature varjations, and drying shrinkage. In general, the summation of crack widths tin a slab of concrete must balance the shrinkage minus the extension of the concrete. Cracks tend to originate at the midpoint between previous cracks. In simple geometries, this leads to a serles of evenly spaced parallel cracks. Addition of stecl reinforcement to the concrete tends to lead to smaller cracks with closer spacing. 'Thus the reinforcement is typically used to control the size and spacing of cracks. Smaller cracks are more likely to heal through autogeneous procasses.

\section{Autogenous Healing of Cracks}

There is considerable evidence for autogenous healing of cracks formed in concrete (Guppy, 1988). Frequently, permeability of concrete has been found to decline with time In flow tests (Loadsman et al, 1988), Healing occurs from carbonation of calcium hydroxide in the cement paste by carton dioxide. Calcium carbonate and hydroxide crystals are found to grow in the crack. Saturation of the crack with water appears to be essential for developing substantial strength from healing (ACI, 1984). Self healing is a very desirable property for materials utllized for radioactlve waste tsolation. The degree to which the self-healing properties of concrete can be "taken credlt for" in quantitative performance assessments remains subject to question and is a fertile area for future research.

\section{Implications of Cracking}

Cracking has tremendous implications for performance of concrete barriers. Cracks represent a preferential pathway for fluid flow and mass transport that bypasses the favorable transport properties of the concrete matrix. In very small cracks, the primary resistance to fluid flow is the passage through the crack itself; however, in larger cracks the primary resistance to flow comes from entrance and exit head losses at the ends of the cracks. The entrance and exit 
head losses are controlled by crack spacing and the permeabillty and thickness of the materials adjacent to the concrete. Frequently tho leakage rate through a concrete slab will be directly proportional to the permeabillty of the adjacent soll or backfill. This fact suggests that low permeability backfill materials should be placed adjacent to concrete vaults if the impacts of cracking are to be minimized. The impacts of cracking on the performance of concrete barriers will be covered in a future NUREG document under the same FIN Number. 


\section{CONCRETE CHEMISTRY, RADIONUCLIDES, AND NEAR FIELD EFFECTS DUE TO CONCRETE}

\section{Radionuclide Geochemistry in Concrete}

The geochemical environment of concrete in a LLLW disposal setting alfects not only the durability of the concrete but also the aqueous chemistry and transport properties of radionuclides that are released throughout the lifetime of a LLW disposal site, Because source term radionuclide concentrations are strongly dependent on the geochemical environment at the source, accurate and defensible modeling and performance assessment analyses of the release of radionuclides from (or through) concrete requires characterization of the temporal variation in concrete chemistry. There are also reeent concerns about the radlonuclide adsorption on colloids with subsequent transport. It is the combination of the physical and chemical properties of the concrete mixture logether with the radionuclide properties that is responsible for radionuclide release and migration. This section briefly discusses the physical and chernical propertics of concrete, the aqueous chem istry of pore fluids in concrete, the temporal variation in pore fluid chemistry within concrete, and the effects of concrete on the chemical behavior of earthen materials in a low-level disposal site. In addition, a discussion of the aqueous chem istry of important radionuclides in a concrete dominated system is presented.

\section{Chemical and Physical Properties of Concrete}

Concrete is composed of a mixture of cement, aggregate, water, and additives such as fly ash or silica flume. Because the chemis:ry of concrete is dominated by reactions that occur in the cement portion of the concrete, the focus of this section is on that chemistry. Portland cement is composed of primarily four compounds: tricalcium silicate $\left(C_{3} S\right)$, dicalcium silicate $\left(\mathrm{C}_{2} \mathrm{~S}\right)$, tricalcium aluminate $\left(\mathrm{C}_{3} \mathrm{~A}\right)$, and tetracalcium aluminoferrite $\left(\mathrm{C}_{4} \mathrm{AH}\right)$. During the curing of concrete, the cement hydrates to form a high surface area microporous matrix that is saturated with an aqueous phase. The composition of the aqueous phase assumes considerable importance in determining the properties of the composite (Angus and Glasser, 1985). Furthermore, the overall permeability and porosity of a concrete is dependent upon both the grain size of the hydrated cement paste and upon the grain size of any additives to the concrete. Because of the fine pore size, the transport and release of radionuclides in concrete will be dorninated by diffusion as long as the concrete is structurally intact. The physical properties of four types of concrete representative of barrier materials are given in Table 4.

Table 4. Properties and constituents of example concretes (Jakubick et al., 1987).

\begin{tabular}{|c|c|c|}
\hline & $\begin{array}{l}\text { Normal } \\
\text { Density - ND } \\
\text { with fly ash }\end{array}$ & $\begin{array}{l}\text { High Density - } \\
\text { HD with silica } \\
\text { fume }\end{array}$ \\
\hline \multicolumn{3}{|l|}{ Properties } \\
\hline $\begin{array}{l}\text { Compressive } \\
\text { Strength ( } 28 \text { days), } \\
\mathrm{MPa}\end{array}$ & $42.0-29.9$ & $39.0-62.6$ \\
\hline Porosity, Vol. \% & $12.8-12.4$ & $9.6-6.5$ \\
\hline $\begin{array}{l}\text { Hydraulic } \\
\text { Conductivity }(\mathrm{m} / \mathrm{s})\end{array}$ & $\begin{array}{l}3.2 \times 10^{-10} \\
4.9 \times 10^{-10}\end{array}$ & $\begin{array}{l}3.9 \times 10^{-10} \\
7.0 \times 10^{-10}\end{array}$ \\
\hline Densily $\left(\mathrm{kg} / \mathrm{m}^{3}\right)$ & $2593-2618$ & $4036-3894$ \\
\hline \multicolumn{3}{|l|}{$\begin{array}{l}\text { Composition, Vol. } \\
\%\end{array}$} \\
\hline Course Aggregate & $38.4-43.3$ & $40.4-40.7$ \\
\hline Fine Aggregate & $30.5-30.0$ & $27.3-27.5$ \\
\hline Fly Astı & 0.3 & \\
\hline Silica Fume & & 3.7 \\
\hline Cement & $12.1-8.6$ & $12.9 \cdot 10.4$ \\
\hline Water & $15.6-14.1$ & $1.50-11.4$ \\
\hline Voids & 3.4 & $4.4-6.3$ \\
\hline
\end{tabular}

The microporous matrix phase of Portland cements (sulfate free) contains a poorly crystalline to amorphis calcium sillcate hydrate (C-S-H) gel and crystalline $\mathrm{Ca}(\mathrm{OH})_{2}$ (portlandite). Although C-H-S exhibits considerable short-range ordering, it is X-ray amorphous because long range ordering is minimal (Grutzek, 1989). C-H-S also exhibits extensive solid solutions and can be formulated as $\mathrm{Ca}_{x} \mathrm{H}_{6 \cdot 2 \mathrm{x}} \mathrm{Si}_{2} \mathrm{O}_{7} \cdot \mathrm{zCa}(\mathrm{OH})_{2} \cdot \mathrm{nH}_{2} \mathrm{O}$ (Glasser, 1987). In addition, the occurrence of aluminates in unhydrated cement results in the formation of silica substituted hydrogarnet (Grutzeck, 1989). The occurrence of alkali oxides $\left(\mathrm{Na}_{2} \mathrm{O}\right.$ and $\left.\mathrm{K}_{2} \mathrm{O}\right)$ in the unhydrated cement dominates the aqueous chemistry of new concrete as discussed below (Angus and Glasser, 1985). The chemical composition of typical cement is given in the Table 5 . 
Table 5. Chemical composition limits of Portland cements (Neville, 1981).

\begin{tabular}{ll}
\hline Oxide & Wt. percent \\
\hline $\mathrm{CaO}$ & $60-67$ \\
$\mathrm{SiO}_{2}$ & $17-67$ \\
$\mathrm{Al}_{2} \mathrm{O}_{3}$ & $3-8$ \\
$\mathrm{Fe}_{2} \mathrm{O}_{3}$ & $0.5-6.0$ \\
$\mathrm{Na}_{2} \mathrm{O}+\mathrm{K}_{2} \mathrm{O}$ & $.02-1.3$ \\
$\mathrm{SO}$ & $1-3$ \\
$\mathrm{MgO}$ & $0.1-4$ \\
\hline
\end{tabular}

\section{Concrete Pore Water Chemistry}

The hydration of cements results in the formation of very alkaline pore fluids. It had been believed that the solubility of portlandite controlled the $\mathrm{pH}$ of pore fluids. However, Glasser et al. (1985) indicate that direct analysis of pore fluids reveals that $\mathrm{NaOH}$ and $\mathrm{KOH}$ are the dominate electrolytes (Table 6); all other things being equal, the alkali concentrations and the $\mathrm{pH}$ of pore fluids are a function of the alkali content of the cement. Since much of the alkali present in cement is rapidly released to the pore fluids (Glasser et al., 1985), the importance of alkali hydroxides in the pore fluid will be temporary. Leaching of the cement by groundwater results in the loss of alkalis, and the $\mathrm{pH}$ of the pore fluid drops as porilandite and C-S-H reactions become important. The early presence of alkalis is unbuffered; once they have been leached from the pore fluid, there is no mechanism to replace them. C-S-H reactions are buffered by the solubility of phases in the hydrated cement. For systems open to the transport of chemical species by groundwater, irreversible reactions will occur in the concrete. An example of such a reaction is the altering of portlandite to calcite by $\mathrm{CO}_{2}$ dissolved in groundwater via

$\mathrm{Ca}(\mathrm{OH})_{2}+2 \mathrm{HCO}_{3}-\mathrm{CaCO}_{3}+\mathrm{H}_{2} \mathrm{O}+\mathrm{CO}_{3}{ }^{2-}$.

Reactions, such as above, coupled with physical displacement of pore water by diffusion dom inated transport results in a gradual loss of buffering capacity. This loss can be visualized as a series of stages with the $\mathrm{pH}$ gradually dropping over time (Atkinson et al., 1988). Because of fluid flow though the disposal site, the expected pH drop will not be uniform. Atkinson (1985) estimates a range of from approximately $10^{4}$ years for the $\mathrm{pH}$ to drop to less than 10.5 in the outer meter of a highly permeable concrete disposal facility in contact with a groundwater, containing reactive species to $2 \times 10^{7}$ years at the center of a disposal facility. An example of the temporal variation of $\mathrm{pH}$ for a groundwater containing reactive ionic species is shown in

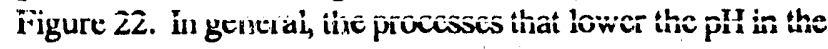
concrete are very slow, requiring time periods on the order of thousands or millions of years for completion. These results suggest that the influence of concrete on the chemical environment of the disposal facility may last for hundreds of thousands of years. Hence, the chemical effects of concrete can far outlast the structural lifetime of the concrete.

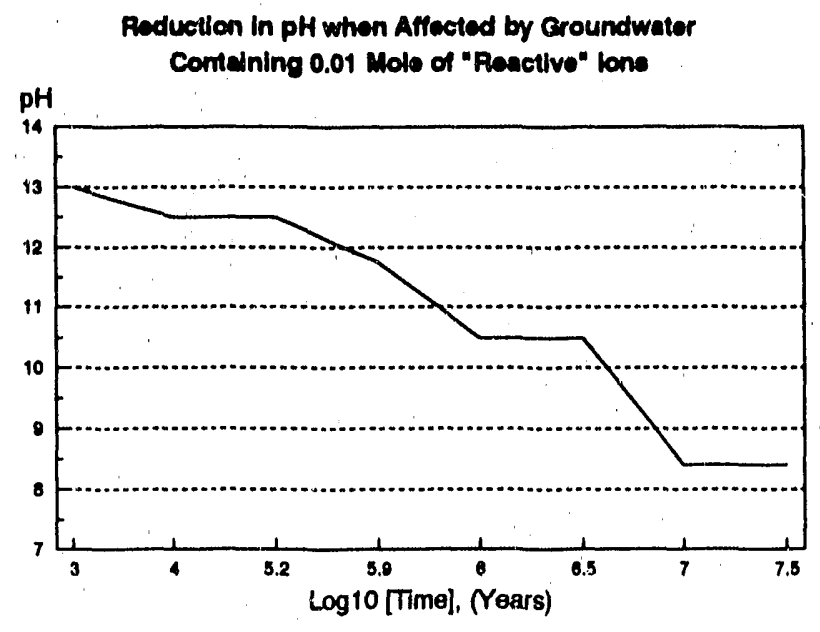

Figure 22. Change in pH with time as predicted by Atkinson et al., 1987.

The redox chem istry of concrete is controlled primarily by additives to the cement. Angus and Glasser (1985) found that the Eh of blastfurnace slag (BFS) cement was slightly oxidizing $(+35$ to $+82 \mathrm{mV})$ and insensitive to composition for OPC:BFS ratios above 0.33. For lower ratios, reducing Eh values as low as $-330 \mathrm{mV}$ were obscrved. However, the addition of zinc or magnesium powder to OPC had no effect on Eh. Tuutti (1982) suggests that nonpassivated mild steel will lower the Eh of pore waters. Eh values of pore water provide insight into the potential redox speciation of radionuclides. However, the long term chemical performance of cement is also a function of its reducing capacity. The reported reducing capacity of BFS is 1.1 mmole $\mathrm{g}^{-1}$ and compares to values of $0.1 \mathrm{mmole}^{-1}$ for OPC and 0.2 for high alumina cement and natural pozzolan (Angus and Glasser, 1985). These results suggest that concrete can be engineered to have pore water Eh values that will ensure that radionuclides with multiple oxidation states (e.g., plutonium) are reduced.

Angus and Glasser (1985) also found that the BFS altered the aqueous speciation of sulfur. For a OPC:BFS ratio of lower than 0.33, aqueous sulfide concentrations of 4 to 34 mmole liter ${ }^{-1}$ were observed by Angus and Glasser (1985). The presence of sulfide in pore water may limit the concentration of radionuclides that are chalcophile elements (e.g., cobalt) by the formation of insoluble sulfide phases. 
Table 6. Measured ranges of pore-water compositions of hydrated cements (Berner, 1987). Composition in mmole liter ${ }^{-1}$ except for $\mathrm{Eh}(\mathrm{mV})$ and $\mathrm{pH}$.

\begin{tabular}{lll}
\hline & Oxidizing $^{\left({ }^{()}\right.}$ & Reducing $^{(\text {b) }}$ \\
\hline $\mathrm{Na}$ & $13-70$ & $78-139$ \\
$\mathrm{~K}$ & $15-200$ & $146-154$ \\
$\mathrm{Ca}$ & $0.4-12$ & $0.5-2.3$ \\
$\mathrm{Mg}$ & $0-0.01$ & $<0.01$ \\
$\mathrm{Si}$ & $<0.2$ & $0-0.2$ \\
$\mathrm{pH}$ & $84-139$ & $-377--196$ \\
\hline
\end{tabular}

a. Based on six cements. b. Based on two cements.

\section{Modification of External Environment by Concrete}

The alkaline cement components that leach from the concrete may have a significant influence on the earthen materials surrounding the concrete barrier. Jefferies $e t$ al. (1988) investigated the response of clays in contact with concrete. They found that the buffering capacities of clays subject to alkali intrusion are best explained by cation exchange of aqueous calcium for sorbed cations and the precipitation of calcite. The saturation of the clay with calcium and the precipitation of calcite may affect the sorptive and hydraulic propertics of the clays. Jefferies $e t$ al. (1988) also state that the $\mathrm{pH}$ of clay pore waters will ultimately rise to about 12 because of the long term chemical efíccts of concrete.

The importance of the potential changes to the surrounding matcrials depends upon the aspect of performance considered. Dispersion and expansion of clays leads to filling gaps and fissures in the system and lowers hydraulic conductivity but results in lower slope and structural stability. The precipitation of calcite "cement" in clay materials may lead to hardening and embrittlement of the clay. In addition, Melchoir et al. (1988) suggest that mineral phase transformation in earthen materials as a result of interactions with concrete needs to be considered.

The affects of $\mathrm{pH}$ on the sorptive properties of radionuclides on clinoptilolite and Dochart clay have been investigated by Buckiey, P̈hilipose et ai. (1988). Tineir results are shown in Figures 23 and 24.

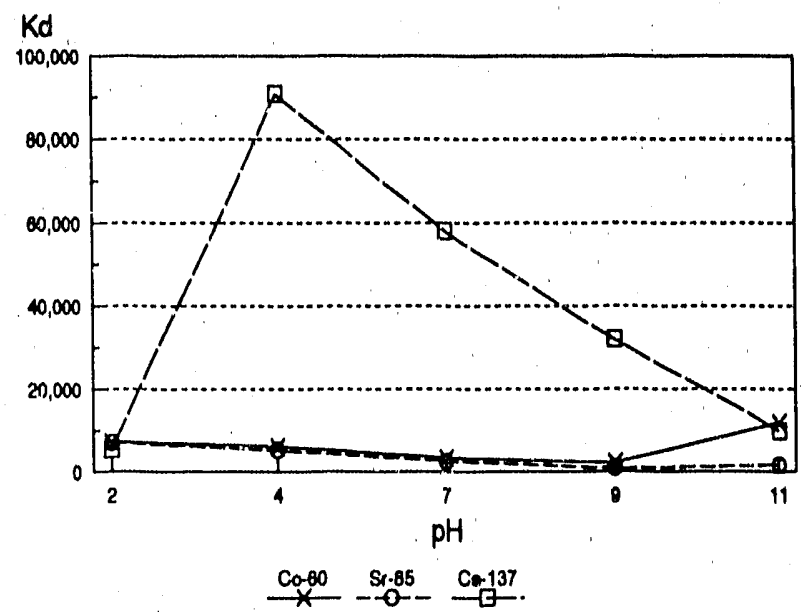

Figure 23. Effect of $\mathrm{pH}$ on distribution coefficient of conditioned clay (Buckley et al., 1988).

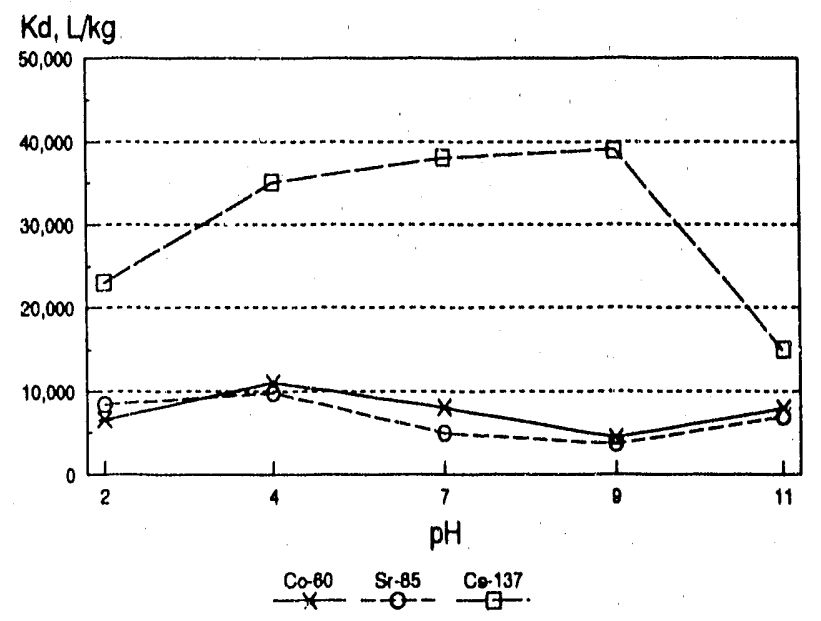

Figure 24. Effect of $\mathrm{pH}$ on distribution coefficient of conditioned clinoptilolite (Buckley et al., 1988).

\section{Radionuclide Behavior}

The radionuclides used to classify waste types in 10 CFR 61 are taken as a starting point for selection of the radionuclides of interest. The primary selection criteria of the regulations are based on radionuclide lifetime and imminent hazard such as reactivity and high probability of uptake to living organisms and humans. Other criteria in addition to these include: expected disposal site environment; radionuclide inventory level; disposal facility performance effects; chemical state; and radioactive progeny. The basis for selection needs further examination. Relative to concrete performance in particular, certain radionuclides, or chemicals in the waste or groundwater, of high chemical reactivity, concentration, and sufficient lifetime could be detrimental to a concrete disposal facility and its concrete components. Reported results from the literature are given beiow for the radionuclides of interest in LLW. 
The aqueous chemistry of radionuclides and other contaminants in concrete will be dominated by the interactions of portlanditc, C-S-H, and additives with the pore fluids. As discussed, the pore fluids are characterized by high $\mathrm{pH}$ values and oxidizing to reducing $\mathrm{Eh}$ values. The concentrations of common inorganic ligands in the pore-fluids are reduced because of the high $\mathrm{pH}$ and calcium concentrations. Carbonate is likely to be removed from ingressed groundwater by the precipitation of calcite. Likewise, phosphate is red ced by the precipitation of apatite $\left[\mathrm{Ca}_{5}\left(\mathrm{PO}_{4}\right)_{3} \mathrm{OH}\right]$ or other insoluble phosphates. The predominate ligands in pore fluid are hydroxide, sulfur species $\left(\mathrm{SO}_{4}^{2-}, \mathrm{S}_{2} \mathrm{O}_{3}{ }^{2-}\right.$, and $\left.\mathrm{HS}\right)$, and perhaps chloride.

Carbon and Carbon-14. Carbon-14 has a half-life of 5,730 years and is casily taken up into the biosphere in solid, liquid, or gaseous compounds. Carbon combines with many other elements to give solid or highly mobile, liquid or gaseous compounds. It is also a primary constituent of living matter. The aqueous chemistry of carbon for disposal facility condition will be dom inated by carbonate equilibria. Hietanen et al. (1985) found that carbon-14 was effectively removed from the aqueous phase in groundwater/concrete tests by the precipitation of calcium carbonate.

lodine and lodine-129. Iodinc- 129 has a half-life of 15.7 million years and is also casily taken up into the biosphere. In humans, iodine is an important chemical in the endocrine system and thyroid. loor all but the most oxidizing conditions, iodide (I) will be the predom inate form of iodine in pore fluids and groundwater. Iodine is more strongly sorbed to hydrated cement than to natural silicates (l löglund et al., 1985), and I will be less mobile in concrete than in neighboring geologic media. Atkins and Glasser (1990) studied the adsorption properties of specific phases in concrete. They found that OPC is a good adsorbent for $\mathrm{I}$ and that the hydrate calcium aluminum sulfates were the best sorbents. The Atkins and Glasser result provides insight into the Iloeglund et al. (1985) observation that the sorption of iodine on BFS cements was lower than for other cements. Because BFS cements are more reducing, significant portions of the sulfate is reduced to sulfide resulting in smaller amounts of hydrate calcium aluminum sulfates.

Actinides. The aqueous chemistry of actinide elements (of interest here are thorium, uranium, neptunium, plutonium, and americium) is characterized by a multiple oxidation state. The behavior of actinides in concrete pore-fluids will be strongly influenced by the Eh. The aqueous chemistry will be dominated by the formation of neutral or anion hydroxide compiexes (Allard, 1983). IIöglund et al. (1985) report high sorption and low mobility of actinides in pore fluid/concrete systems. They also observed that the sorption behavior (as measured by $\mathrm{K}_{\mathrm{d}}$ ) is very similar for trivalent (Am), tetravalent (Th), pentavalent
(Np), hexavalent $(\mathrm{U})$, and mixed valent $(\mathrm{Pu})$ actinides. These results suggest that concrete can be an extremely effective barrier to actinide migration.

Hydrogen and Tritium. Hydrogen-3, tritium has a half-life of 12.3 years and can replace hydrogen in most of its compounds. Tritium is very mobile in most circumstances, and because it is present as tritiated water, it will not interact significantly with water saturated concrete. Uncoated concrete absorbs water rapidly, and once wetted, conducts tritium in the waters at about $8 \times 10^{-4}$ $\mathrm{cm}^{3} \mathrm{~cm}^{-2}$ day ${ }^{-1}$ (Eichholz et al., 1989). Diffusion rates can be reduced by finishing the concrete surface or using a smaller aggregate size and vibratory packing. Unless a concrete wall is coated or sealed in some way, little credit can be taken for concrete as a retarding barrier (Eichholz et al., 1989). Harris (1988) reports that the transport of tritum is not hindered by concrete.

Technetium and Technetium-99. Technetium 99 has a half-life of 2.6 million years and in oxidized form $\left(\mathrm{TcO}_{4}{ }^{-}\right)$ is highly soluble and casily taken up in the biosphere. The aqueous chem istry of technetium in concrete pore fluids can be very complex because for oxidizing conditions, the highly soluble pertechnetate ion dominates. Tallent et al., (1988) investigated the behavior of pertechnetate and nitrate in BFS cement-based materials. They found that the inclusion of BFS reduced the release of technetium but not nitrate and attribute this difference to reduction of pertechnetate to the tetravalent oxide. Lee and Bondietti (1983) indicate that ferrous iron or sulfide bearing waters decrease the mobility of technetium by precipitating reduced technetium bearing iron and sulfide phases. These results suggest that technetium can be effectively retarded by engineering the chemical properties of concrete barriers.

Cobalt and Cobalt-60. Cobalt-60 has a half-life of 5.3 years and can become resident in bone structures. Cobalt occurs as anionic hydroxide species in pore fluids (Baes and Mesmer, 1976). Cobalt (II) hydroxide has a minimum solubility in the $\mathrm{pH}$ range of 10.2 to 11.5 . The concentration of cobalt in pore fluids may be suppressed further by substituting for calcium in portlandite and C-S-H. Habayeb (1985) found that release of cobalt-60 from cement waste forms was below detection levels.

Strontium and Strontium-90. Strontium-90 has a half life of 28.5 years, readily replaces calcium in carbonate compounds, and becomes resident in bone structures. Strontium is retarded by BFS concretes (Harris, 1988). In concrete pore fluids, strontium will occur as $\mathrm{Sr}^{2+}$ and $\mathrm{Sr}(\mathrm{OH})^{+}$. Because of the similarities between calcium and strontium, theses two ions compete for similar sites and ligands in concrete. Therefore, the sorption/precipitation of strontium is a function of the Ca:Sr ratio of the fluid. Jakubick et al. (1987) found that the sorption of strontium onto concrete is greater for sodium chloride solution than 
for calcium chloride solutions. In addition, during calcite precipitation, strontium is preferentially enriched in the fluid phase relative to calcium (Mucci and Morse, 1983). Sorption experiments with concrete indicate that strontium is only weakly adsorbed (Jakubick et al., 1987; Hietanen $e t$ al., 1985).

Cesium and Cesium-137. Cesium-137 has a half-life of 30 years. Hoyle and Grutzeck (1988) incorporated cesium hydroxide in cement and observed complete removal of cesium from a solution in the form of cesium zcolites. They also observed that cesium fixation increased as the amount of calcium decreased and the ratio of $\mathrm{Al}: \mathrm{Si}$ increased. Grutzeck (1989) reports that the concrete phases that form affect the chem istry of the remaining pore solution and tailoring concrete with silica or BFS can reduce the pore solution composition of cesium and strontium by a factor of 10. Furthermore, decreasing the activity of the calcium in the system led to a decrease in the amount of cesium and strontium leached by a factor of ten. Hictanen et al. (1985) found high sorption of cesium in tests made with natural ground waters. However, the sorption of cesium on concrete is due primarily to adsorption on the aggregate. Robertson
(1984) notes preferential sorption of Cesium-137 and Cesium-134 on unfinished or eroded concrete surfaces used in reactors. The behavior of cesium in concrete is compositionally dependent, with the formation of cesium bearing zeolitic phases limiting cesium mobility.

\section{Summary}

Concrete acts as a effective barrier for the migration of most radionuclides The potential problem nuclides are tritium, iodine, strontium, technetium, and cesium. Design consideration of the chemical environment in concrete can result in substantial improvement of concrete as a barrier to radionuclide migration. The mobillty of radionuclides can be reduced in most cases by a factor of 10 and in some cases by a factor of 100 . The transport and release of radionuclides in concrete will be primarily by diffusion as long as the concrete is structurally intact. Longer curing (Craw ford $e t$ al., 1985) or the custom tailoring of concrete can achieve reduced permeability and porosity, reduced leachability, lower diffusion rates, and increased sorption for most radionuclides (Harris, 1988; Grutzeck, 1989; Izumida et al., 1987). 


\section{SUMMARY AND CONCLUSIONS}

This report has summarized and critically evaluated some of the models available for estimating long-term degradation of concrete barriers. A companion report will evaluate the implications of degradation on fluid flow and mass transport through concrete barriers. It is apparent that available models are limited in terms of scope and validity. Although more sophisticated models are continuously being developed, all the inherent problems will not be resolved soon. Several problem areas are discussed below.

Concrete longevity is dependent upon quality, much more so than most materials. This high dependence on the quality of cement; aggregate type, size, and quantity; water-to-cement ratio; and workmanship severely limits our ability to quantitatively estimate performance. A simple example comes from the building where one of the authors works. Outside the back door are two rain spouts constructed from concrete. In the approximately 5 years the building has been in existence, one of the rain spouts evidences no visual damage while the other spout has completely degenerated into a rubble heap. Although quality assurance levels can be expected to be much higher in LLW disposal facility construction, leading to more consistent concrete quality, the observation nonetheless illustrates the potential problems with predicting long-term concrete performance.

The sections on individual types of concrete attack do not address the combined or coupled effect of all processes working simultancously. In the Barrier code (Shuman $e t$ al., 1989), the coupled attack is simulated with annual changes in the properties of each concrete layer. Processes such as sulfate attack and frecze/thaw are assumed to lead to annual reductions in the effective thickness and transport properties of the concrete slab. For example, a loss in thickness of the outer roof surface translates into a reduction in the steel reinforcement cover thickness, causing more rapid initiation of corrosion. Since most of the empirical concrete degradation models were based upon data from a single type of attack on concrete samples with fixed dimensions, the approach is not necessarily valid in all cases. However, in the absence of more detailed information, this may be the best available option. The coupling approach applied in the Barrier code is at least more conservative (i.e., predicts more rapid degradation) than separate applications of each degradation model, such as the example calculations included at the end of most sections in this document.

The models that currently exist have almost entirely been derived from the point of view of external attack. Prediction of attack rates from materials included in the wastes will be made more difficult by the absence of appropriate models.
Our ability to model concrete performance is limited on all sides. The empirical concrete degradation models included in this report are of necessity applied outside their range of validity when evaluating long-term performance of concrete. Mechanistic models, where avallable, frequently lack adequate parameter data bases. In some cases, the mechanistic models predict trends that directly conflict with experimental and historical data.

The lack of adequate models and physical understanding for many of the degradation processes makes the application of Monte-Carlo and other statistical techniques to account for uncertainty of questionable validity. Statistical techniques that propagate parameter uncertainties cannot account for basic uncertainties or lack of understanding in the conceptual model of the wasie isolation system. Given the current state of model development, the classical conservative analysis mode of calculations may be most appropriatc.

Cracking of the concrete is one of the most difficult types of degradation because it is very difficult to predict where and when cracks will occur. Although predictive models are available for cracking in simple structural arrangements (e.g., flexural beams), their application to complex underground structures over long time periods remains questionable. The difficulty of predicting crack occurrence must then be combined with significant changes to permeability of the concrete. Even a very small crack can change the transport properties of a concrete slab by orders of magnitude. After formation, the cracks may self heal over timc, although the specifics of when autogenous healing will occur are not clear. In cases where crack formation is not expected, it is difficult to clearly demonstrate in a performance assessinent that no cracks will form. Questions such as the following are of prime importance to understanding and predicting the long-term performance of concrete barriers: When and where will cracks occur?, Under what conditions does autogenous healing occur?, and What is the impact of cracks upon performance of the concrete barrier? A future publication will analyze the impact of cracking on concrete performance.

The geochemical properties of concrete offer great promise because they are long lasting and robust, and concrete chemistry shows promise for significant retardation of carbon and iodine, two radionuclides that are difficult to contain.

Further development work is needed in all areas of concrete degradation. A major priority should be in the analysis of cracking and autogenous healing of cracks. Cracking is the one degradation process that is most difficult to predict and can have the greatest impact upon performance. 


\section{BIBLIOGRAPHY}

American Concrete Institute Committee 222, "Corrosion of Metals in Concrete," ACI Journah, p. 3-32, January February, 1985.

American Concrete Institute Committce 224, "Causes, Evaluation, and Repair of Cracks in Concrete Structures," ACI Journal, p. 211-230, May-June, 1984.

Alcorn, S. R., J. Myers, M. A. Gardiner, and C. A. Givens, "Chemical Modeling of Cementitious Grout Materials Alteration in HLW Repositories," Waste Management 89, University of Arizona, p. 279-286, 1989.

Alford, N. McN., and A. A. Rahman, "An Assessment of Porosity and Pore Sizes in Hardened Cement Pastes," Journal of Materials Science, 16, p. 3105-3114, 1981.

Allard, B. (1983) Actinide Solution Equilibria and Solubilities in Geologic Systems, SKBF/KBS Teknisk Rapport 83-35, Svensk Kärnbränslefösörjning $\mathrm{AB} /$ Avdelning KBS, Stockholm, Sweden.

Angus, M.J. and Glasser, F.P., "The Chemical Environment in Cement Matrices, Scientific Basis for Nuclear Waste Management VII," Materials Research Society Reseach Symposium Proceedings, 50, p. 547-556, 1985.

Atkins, M., and F.P. Glasser, "Encapsulation of Radioiodine in Cementitious Waste Forms," Materials Research Society, 176, p. 15-22, 1990.

Atkinson, A., The Time Dependence of pH Within a Repository for Radioactive Waste Disposal, AERE Harwell Report No. DOE/RW/85.062, 1985.

Atkinson, A., A. K. Nickerson, and T. M. Valentine, "The Mechanism of Leaching From Some Cement-Based Nuclear Wasteforms," Radioactive Waste Management and the Nuclear Fuel Cycle, 4(4), p. 357-378, 1984.

Atkinson, A., and J. A. Hearne, An Assessment of the Long-Term Durability of Concrete in Radioactive Waste Repositories, AERE-R11465, Harwell, U.K., 1984.

Atkinson, A., D. J. Goult, and J. A. Hearne, "An Assessment of the Long-Term Durability of Concrete in Radioactive Waste Repositories," Materials Research Society, 50, p. 239-246, 1985.

Alkinson, A., F.T. Ewart, S.Y.R. Pugh, H.H. Rees, S.M. Sharland, P.W. Tasker, and J.D. Wilkins, "Experimental and Modeling Studies of the Near-field Chemistry for Nircx Repository Concepts", Near-Field Assessment of Repositories for Low and Medium Level Radioactive Waste, Nuclear Encrgy Agency, OECD, Paris, p. 143-157, 1988.
Atkinson, A. and J. A. Hearne, "Mechanistic Model for the Durability of Concrete Barriers Exposed to Sulphate-Bearing Groundwaters," Materials Research Society, 176, p.149-156, 1990.

Atkinson, A. and A. K. Nickerson, "Diffusion and Sorption of Cesium, Strontium, and Iodine in Water-Saturated Cement," Nuclear Technology, 81, p. 100-113, 1988.

Baes, C.F., and R.E. Mesmer, The Hydrolysis of Cations, Wiley Interscience, New York, pp. 489, 1976.

Bazant, Z. P., J. Chem, A. M. Rosenberg, and J. M. Gaidis, "Mathematical Model for Freeze-Thaw Durability of Concrete," J. Am. Ceram. Soc., 71(9), p. 776-783, 1988.

Bazant, Z. P., "Physical Model for Sicel Corrosion in Concrete Sea Structures - Theory," ASCE Structural Division Journal, 105(6), p. 1137-1153, 1979a.

Bazant, Z. P., "Physical Model for Steel Corrosion in Concrete. Sea Structures - Application," ASCE Structural Division Journal, 105(6), p. 1155-1166, 1979 b.

Bazant, Z. P. and B. H. Oh, "Spacing of Cracks in Reinforced Concretc," ASCE Journal of Structural Engineering, 109(9), p.2066 - 2085, 1983.

Bazant, Z. P. and W. J. Raftshol, "Effect of Cracking in Drying and Shrinkage Specimens," Cement and Concrete Research, 12, p. 209-226, 1982.

Broms, B. B, and L. A. Lutz, "Effects of Arrangement of Reinforcement on Crack Width and Spacing of Reinforced Concrete Members," Journal Amer. Concrete Institute, 10, p. 1395 - 1409, 1965.

Broms, B. B., "Crack Width and Crack Spacing in Reinforced Concrete Members," Journal Amer. Concrete Institute, 10, p. 1237 - 1255, 1965.

Buckley, L.P., Philipose, K.E. and Torok, J., "Engineered Barricrs and Their Influence on Source Behavior", IAEA Conference Proceedings on: Management of Low and Intermediate Level Radioactive Wastes, 1, p. 147-161, 1988.

Clear, K. C., Time to Corrosion of Reinforcing Steel in ConcreteSlabs, Vol.3. Performance Agter 330 Daily Salt Applications, Federal Highway Administration Report No. FIIWA-RD-76-70, NTIS PB-2.58 446, 1976.

Clifton, J. R., The Frost-Resistance of Concrete, NISTIR 90-4229, National Instilute of Stanuards and Technology, 1990. 
Codell, R. B. and J. D. Duguid, "Transport of Radionuclides in Groundwater," J. E. 'Tll1 and H. R. Meyer ed., Radiological Assessment: A Textbook on Environmental Dose Analysis, NUREG/CR-3332, 1983.

Crank, J., The Mathematics of Diffusion, Oxford University Press, Oxford, 1975.

Crawford, R.W., F.P. Glaser, A.A. Rahman, M.J. Angıs, and C.E. McCulloch, "Diffusion Mechanisms and Factors Affecting Leaching of Cacsium-134 from Cement Based Waste Matrices," Radioactive Waste Management and the Nuclear Fuel Cycle, 6, p. 177-196, 1985.

Daian, J., "Condensation and isothermal Water Transfer in Cement Mortar, Part I - Pore Size Distribution, Equilibrium Water Condensation and Imbibition," Transport in Porous Media, 3, p. 563-589, 1988.

Detwiler, R. J., B. J. Dalgleisch, and R. B. Williamson, "Assessing the Durability of Concrete in Freezing and Thawing," ACI Materials Journah, p. 29-35, 1989.

Eichholz, G.G., Park, W.J., and Hazin, C.A., "Tritium Penetration Through Concrete," Waste Management, 9, p. 27-36, 1989.

Glasser, F.P., M.J. Angus, C.E. McCulloch, D. Macphec, and A.A. Rahman, "The Chemical Environment in Cements," Materials Research Society, 44, p. 849-858, 1985.

Grutzck, M.W., Physical Chemistry of Portland Cement Hydrate, Radioactive Waste IIosts, US DOE Report No. DOE/ER/45145--4, January 1989.

Guppy, R., Autogenous Healing of Cracks in Concrete and its Relevance to Radwaste Repositories, NSS/R-105, DE88 753994, Nirex, United Kingdom, 1988.

Habaycb, M.A., "Isaching Performance of Cemented Decontamination Wastes," Nuclear and Chemical Waste Management, 5, p. 305-314, 1985.

Harker, A. H., S. M. Sharland, and P. W. Tasker, "A Mathematical Model of Uniform Corrosion of Intermediate Level Radioactive Waste Canisters in Concrete," Radioactive Waste Management and the Nuclear Fuel Cycle, 8(1), p. 65-85, 1987.

Harris, A.W., A. Alkinson, A.K. Nickerson, and N.M. Everitt, Mass-Transfer in Water Saturated Concretes, Safety Studies Nirex Radioactive Waste Disposal, NSS/R125, Harwell Laboratory, Didcot, Oxon, UK, 1988.

Harrison, W. H., and D. C. Teychenné Sulphate Resistance of Buried Concrete: Second Interim Report on Long Term Investigation at Northwick Park, Building Rescarch Establishment, Her Majesty's Stationery Office, London 1981.
Hem, J. D., Study and Interpretation of the Chemical Characteristics of Natural Water, USGS Water-Stıpply Papcr, pp. 1473, 1970.

Hietanen, R., T. Jaakola, and J.K. Miettinen, "Sorption of Cesium, Strontium, Iodine and Carbon in Concrete and Sand, "Materials Research Society, 44, p. 891-898, 1985.

Hillel, D., Soil and Water Physical Principles and Processes, Academic Press, New York, 1971.

Höglund, S., L. Eliasson, B. Allard, K. Andersson, and B. Torstenfelt, "Sorption of Some Fission Products and Actinides in Concrete Systems," Materials Research Socie'y, 50, p. 683-690, 1985.

Hornc, R. A., The Chemistry of Our Environment, Wiley Interscience, New York, 1978.

Hoyle, S.L. and M.W. Grutzek, "Fixation of Cesium by Calcium Aluminosilicate Hydrates," Materials Research Society Reseach Symposium Proceedings, 112, p. 13-21, 1988.

Izumida, T. F. Kawamura, K. Chino, and M. Kikuchi, "Stability of Cement-Glass Packages Containing Borate Sall Gencrated from Pressurized Water Reactor Power Plants," Nuclear Technology, 78, p. 185-190, 1987.

Jakubick, A. T., R. W. Glllham, I. Kahl, and M. Robin, "Allenuation of Pu, Am, Cs and St Mobility in Concrete," Materials Research Society, 84, p. 355, 1987.

Jefferics, N. L., C. J. Tweed, and S. J. Wisbey, "The Effects of Changes in pH Within a Clay Surrounding a Cementitious Repository," Mat. Res, , 112, p. 43-52, 1988.

Klieger, P., "Durability Studies at the Portland Cement Association," Durability of Building Materials and Components, ASTM STP 691, P.I. Sereda and G.G. Litvan, Eds., American Society of Testung and Materials, p. 282,-300, 1980.

Lancy et al., Subsurface Investigations Program at the Radioactive Waste Management Complex of the Idatio National Engineering Laboratory, Annual Progress Report: FY-1987, DOE/ID-10183, 1988.

Lca, F. M., The Chemistry of Cement and Concrete, 3rd Ldition, Ldward Amold Ltd., London, 1970.

Lec, Y.S., and Bondetti, E.A., "Technetium Behavior in Sulfide and Ferrous Iron Solutions," Materials Research Society, 15, p. 315-322, 1983.

Likens, G. E., F. H. Bormann, R. S. Pierce, J. S. Eaton, and N. M. Johnson, Biogeochemistry of a Forested Ecosystem, Springer-Verlag, New York, 1977.

Loadsman, R. V. C., D. H. Acres, C. J. Stokes, and L. Wadcson, A Study of the Water Permeability of Concrete Structures, DOE Report No: DOE/RW/88052, United Kingdom, 1988. 
Melchior, D., R. Glazier, and R. Marton, "Geochemical Performance of Earthen and Cementitious Sealing Materials for Radioactive Waste Repositories," Waste Management '88, University of Arizona, p. 745 - 751, 1988.

Muccl, A., and J.W. Morse, "The incorporation of $\mathrm{Mg}^{2+}$ and $\mathrm{Sr}^{2+}$ into Calcite Overgrowths: Influences of Growth Rate and Solution Composition," Geochim. Cosmochim. Acta, 47, 217-233, 1983.

Neville, A. M., Properties of Concrete, 3rd Edition, John Wiley \& Sons, New York, 1981.

Newman, J., Electrochemical Systems, Prentice Hall, New Jersey, 1973.

Oh, B. H. and Y-J Kang, "New Formulas for Maximum Crack Width and Crack Spacing in Reinforced Concrete Flexural Members," ACI Structural Journal, p. 103-112, March-April, 1987.

Papadakis, V. G., C. G. Vayenas, and M. N. Fardis, "A Reaction Engineering Approach to the Problem of Concrete Carbonation," AIChE Journal, 35(10), p. 1639-1650, 1989.

Pigeon, M., and M. Lachance, "Critical Air void Spacing Factors for Concretes Submitted to Slow Freeze-Thaw Cycles," ACI Journal, p. 282-290, 1981.

Pigeon, M., J. Prevost, and J. Simard, "Freeze-Thaw Durability Versus Freczing Rate," ACI Journah, p. 684-692, 1989.

Portland Cement Association, Effects of Substances on Concrete and Guide to Protective Treatments, PCA Publication ISO01.0T6, 1986.

Powers, T. C., A Hypothesis on Carbonation Shrinkage, PCA Research Department Bulletin 146, 1962.

Powers, T. C., Physical Properties of Cement Paste, PCA Research Department Bulletin 154, 1960.

Powers, T. C., "Structure and Physical Properties of Hardened Portland Cement Paste," Journal American Ceramic Society, 41(1), p. 1-6, 1958.

Rasmuson, A., I. Neretnieks, and M. Zhu, "Calculations of the Degradation of Concrete in a Final Repository for Nuclear Waste" Proceedings of an NEA Workshop on Near-Field Assessment of Repositories for Low and Medium Level Radioactive Waste, Baden, Switzerland, 1987.
Robertson, D.E., K.H. Abel, C.W. Thomas, E.A. Lepel, W.V.Thomas, L.C. Carrick, M.W. Leale, and J.C. Evans, "Residual Radionuclide Contamination With and Around Nuclear Power Plants: Origins, Distribution, Inventory and Decommissioning Assessment" Radioactive Waste Management and the Nuclear Fuel Cycle 5, 285-310, 1984.

Shuman, R., V. C. Rogers, and R. A. Shaw, "The Barrier Code for Predicting Long-Term Concrete Performance," Waste Management 89, University of Arizona, 1989.

Stark, D., Longtime Study of Concrete Durability iu Sulfate Soils, PCA SP-77, 1982.

Subramanjan, E. V., and H. G. Wheat, "Depassivation Time of Stecl Reinforcement in a Chloride Environment - A One-Dimensional Solution," Corrosion, 45(1), p.43-48, 1989.

Tallent, O.K., E.W. McDaniels, C.D. Del Cul, K.E. Dodson, and D.R. Trotter, "Immobilization of Technetium and Nitrate in Cement-based Materials," Materials Research Society, 112, p. 23-32, 1988.

Turnbull, A., British Corrosion Journal, 15(4), 1980.

Tuutti, K., Corrosion of Steel in Concrete, Swedish Cement and Concrete Research Institute, Stockholm, 1982.

Verbeck, G. J., Carbonation of Hydrated Portland Cement, PCA Research Department Bulletin 87, 1958.

Walton, J. C., and B. Sagar, "A Corrosion Model for Nuclear Waste Containers," Scientific Basis for Nuclear Waste Management X, Materials Research Society, 84, p. 271 $-282,1987$.

Walton, J. C., and B. Sagar, "Modeling Performance of Steel Containers in High-Level Waste Repository Environments: Implications for Waste Isolation," Radioactive Waste Management and the Nuclear Fuel Cycle, Vol. 9(4), p. 323-347, 1988.

Wang, J. S. Y. and T. N Narasimhan, "Hydrologic Mechanisms Governing Fluid Flow in a Partially Saturated, Fractured, Porous Medium," Water Resour. Res., 21(12), p. 1861-1874, 1985.

Wosten, J. H. M. and van Genuchten, M. Th. Using texture and other soil properties to predict the unsaturated soil hydraulic functions, Soil Sci. Soc. Am Journal, 52, p. 1762-1770, 1988.

Yonczawa, T., V Ashworth, and R. P. M. Procter, Pore Solution Composition and Chloride Effects on the Corrosion of Steel in Concrete, Corrosion, 44(7), p. 489-499, 1988. 


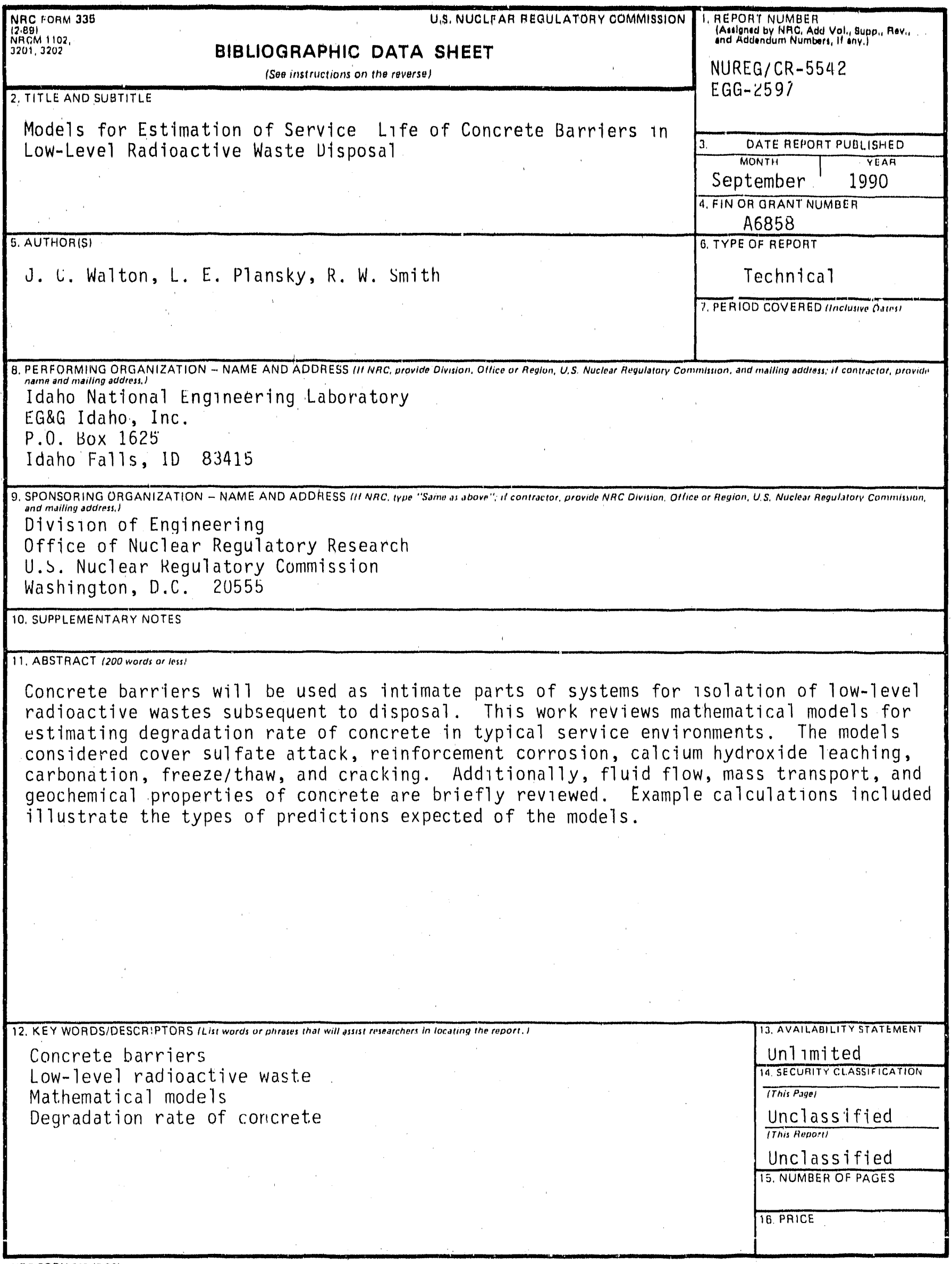



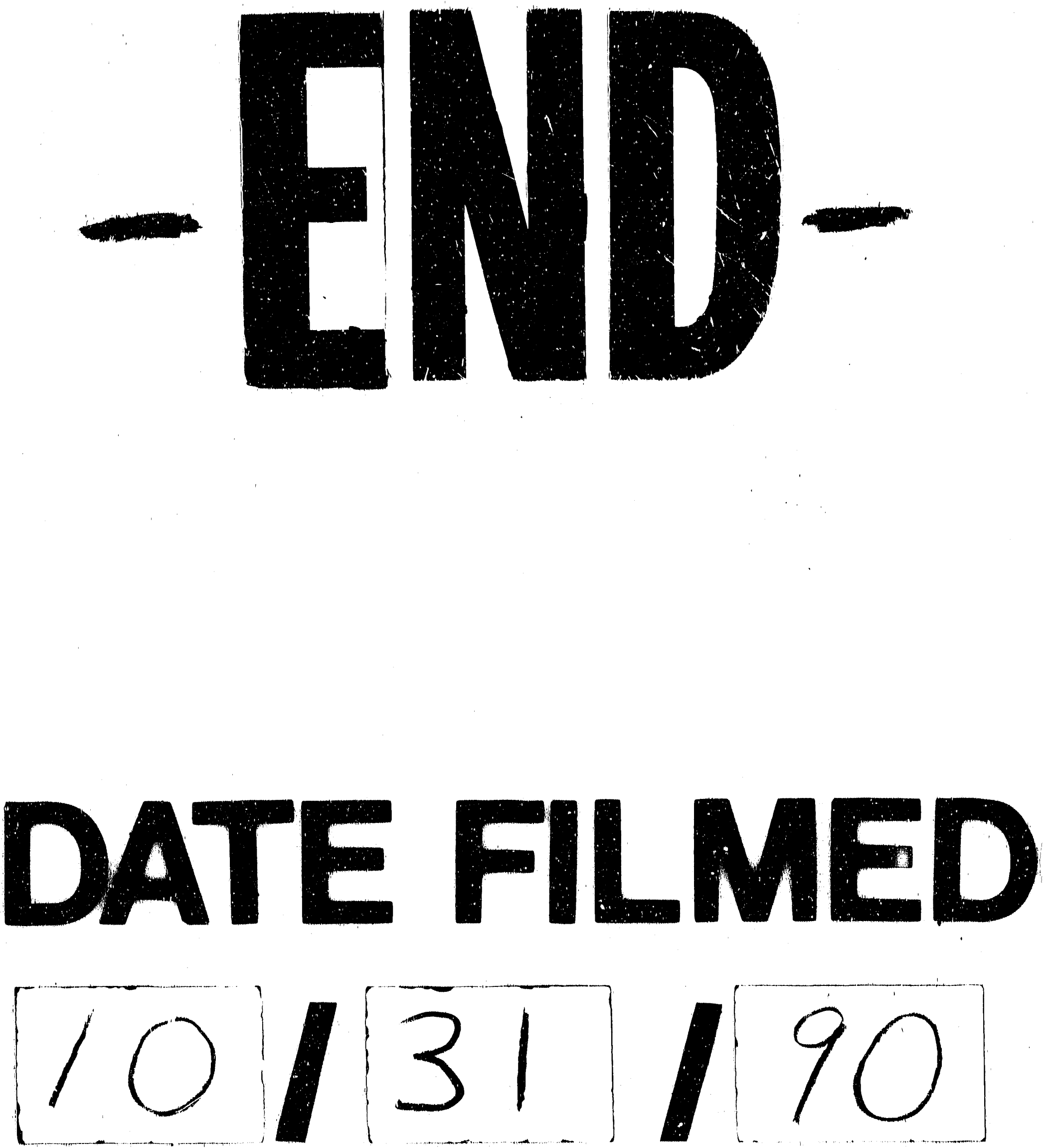
